\section{GLOSSÁRIO DOS HERMETICA GRACCA: PESQUISA BIBLIOGRÁFICA DAS FERRAMENTAS E DAS FONTES SECUNDÁRIAS DE TRADUÇÃO}

\author{
David Pessoa de Lira* \\ Recebido em: 22/02/2021 \\ Aprovado em: 29/06/2021
}

*Professor Adjunto, Departamento de Letras, Universidade Federal de Pernambuco.

\begin{abstract}
RESUMO: O Glossário dos Hermetica Graca compreende 500 entradas ou lemas extraídos das ocorrências no Greek-English Lexicon de LiddellScott-Jones (LSJ), no Diccionario Griego-Español (DGE) de Francisco Rodríguez Adrados e no Greek Lexicon of the Roman and Byzantine Periods de Apostolides Sophocles. Predominantemente, são palavras que procedem das duas maiores coleções herméticas, a saber, do Corpus Hermeticum e dos Stobaei Hermetica. Este trabalho, por meio de uma pesquisa bibliográfica, objetiva apresentar os instrumentos de trabalho disponíveis para a tradução dos Hermetica Graca. A pesquisa perscruta e examina as fontes secundárias, a saber, dicionários e léxicos gerais da língua grega, com a finalidade de encontrar lemas que remetem aos Hermetica Graca, classificálos e quantificá-los.
\end{abstract}

PALAVRAS-CHAVE: Hermetica Graca; glossário; léxico; texto grego; tradução; pesquisa bibliográfica; fontes secundárias.

\author{
GLOSSARY OF THE HERMETICA GRÆCA: \\ BIBLIOGRAPHIC SURVEY OF TOOLS AND \\ SECONDARY SOURCES OF TRANSLATION
}

\begin{abstract}
The Glossary of Hermetica Graca comprises 500 entries or lemmata extracted from occurrences in the Greek-English Lexicon of Liddell-Scott-Jones (LSJ), in the Diccionario Griego-Español (DGE) by Francisco Rodríguez Adrados and in the Greek Lexicon of the Roman and Byzantine Periods by Apostolides Sophocles. Predominantly, these are words from the two largest hermetic collections, namely, the Corpus Hermeticum and the Stobaei Hermetica. This paper, through a bibliographic survey,
\end{abstract}


aims to present the working tools available for the translation of the Hermetica Graca. The survey searches and examines the secondary sources, namely dictionaries and general lexicons of the Greek language, classifying and quantifying lemmata that refer to the Hermetica Graca.

KEYWORDS: Hermetica Graca; glossary; lexicon; Greek text; translation; bibliographic survey; secondary sources.

\section{INTRODUÇÃo}

$\mathrm{O}$

presente texto objetiva, por meio de uma pesquisa bibliográfica (lexical, vocabular, de dicionário e de glossário), apresentar e discutir os instrumentos de trabalho disponíveis para a tradução dos Hermetica Graca, ou seja, do conjunto de escritos herméticos assim designado em latim, composto pelas seguintes obras: Corpus Hermeticum, Asclepius Latinus, Stobaei Hermetica, Tratados 6, 7, 8 do codex VI Nag Hammadi, Fragmenta Hermetica, Definições Herméticas Armênias e Fragmentos do Papiro de Viena (Lira, 2015, p. 43). Os Hermetica Graca filosófico-religiosos são textos herméticos escritos e conservados em grego. Eles compreendem o Corpus Hermeticum, algumas passagens gregas do Logos Teleios (original do Asclepius Latinus), os Stobaei Hermetica Excerpta (Stobaei Hermetica), a maioria dos Fragmenta Hermetica em obras de vários filósofos, teólogos e pensadores, e Fragmentos do Papiro de Viena. Na presente pesquisa serão abordadas as palavras dos textos exclusivamente gregos. Daí a designação de Hermetica Graca neste texto.

Esses escritos herméticos foram produzidos na época imperial romana e possuem um conteúdo filosófico-religioso caracterizado por esquemas teoantropocósmicos e éticosoteriológicos. A pesquisa, a partir de uma abordagem metodológica indutiva, perscruta e examina as fontes secundárias, a saber, dicionários e léxicos gerais da língua grega, como o Greek-English Lexicon de Liddell e Scott, o Diccionario Griego-Español (DGE) de Francisco Rodríguez Adrados e o Greek Lexicon of the Roman and Byzantine Periods de Apostolides Sophocles, com a finalidade de encontrar lemas que remetem aos Hermetica Graca, classificálos como tal e quantificá-los (Eco, 1985, p. 37-38; Kahlmeyer-Mertens et al., 2009, p. 35; Marconi; Lakatos, 2010, p. 68-73, 157-9, 166-8).

Proceder a uma tradução dos Hermetica Graca exige dados tanto dos textos gregos críticos como de dicionários, léxicos e indices especializados do grego antigo, léxicos filosóficos e religiosos, além de outros livros voltados para o objeto de estudo, a saber, Literatura Hermética e Hermetismo, uma vez que se faz necessário estabelecer regularidades para identificar os usos específicos de palavras em determinados ambientes e literaturas, suas acepções precisas e as alternâncias de sentido, constituindo-se como parte das técnicas de pesquisa e de estudo (Rossetti, 2006, p. 251-2). Não obstante, mesmo que houvesse um léxico especializado nos Hermetica Graca, certamente não se esperaria que ele cobrisse todos os lemas e lexemas desses textos e novamente se haveria de recorrer a um léxico mais amplo, como o de Liddell-Scott-Jones (LSJ), sobre o qual se discorrerá a posteriori. Esse fato não aconteceria apenas com os Hermetica Graca, mas com qualquer léxico especializado (McLean, 2014, p. 1). 
Não há dúvida de que enciclopédias, dicionários e léxicos de filosofia e religião são abundantes. Há também artigos e livros que aprofundam determinadas noções, que analisam o léxico de determinados tratados herméticos ou de um autor hermético em específico. ${ }^{1}$ No Lessico Filosofico dell" "Asclepius" de Marco Bertolini, há um estudo sobre as palavras latinas de cunho filosófico que serviram para traduzir termos gregos variados. No caso de $O$ bilinguismo

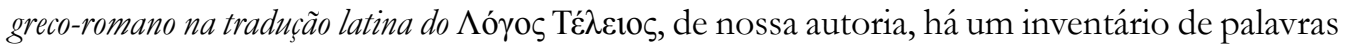
gregas, de empréstimos e de comutação de código, além das frequências desses fenômenos. ${ }^{2}$

Em todo caso, em geral, há uma escassez de manuais que explorem e analisem sistematicamente os termos, suas acepções e usos cunhados pelos filósofos gregos e latinos (Rossetti, 2006, p. 252). Em língua portuguesa, ainda não há dicionários ou léxicos especializados nos Hermetica Graca (com exceção de publicação recente, Grego antigo instrumental, que empregou exemplos de palavras, orações e textos do Corp. Herm., incluindo listas de vocábulos gregos que incidem majoritariamente mais de nove vezes nos textos herméticos). ${ }^{3}$ Esse livro contém várias listas de palavras extraídas do Corp. Herm., com aproximadamente 300 entradas, que não se configuram necessariamente entre os lemas e lexemas que incidem no Greek-English Lexicon de Liddell e Scott, no Diccionario Griego-Español (DGE) de Francisco Rodríguez Adrados e no Greek Lexicon of the Roman and Byzantine Periods de Apostolides Sophocles. Sublinhe-se, então, um dado importante: essas palavras foram selecionadas diretamente do Corp. Herm.

Para uma pesquisa bibliográfica, no entanto, fez-se necessário empregar dicionários e léxicos estrangeiros de grego que apresentassem as acepções herméticas, indicando as incidências de sentido em um contexto específico. Por esta razão, recorreu-se ao LSJ e ao DGE en linea ou online. Este último vai além das referências e empregos mencionados pelo primeiro. No entanto, infelizmente, o DGE en linea não passa da letra E (épsilon), ou seja, cobrindo apenas a seção alfabética $\alpha-\check{\varepsilon} \xi \alpha v o \zeta$, incluindo 60.000 entradas e 370.00 citações ou referências gregas. Outrossim, o Greek Lexicon of the Roman and Byzantine Periods (from B.C. 146 to A.D. 1100) de Apostolides Sophocles menciona as ocorrências e acepções de várias palavras gregas dos tratados do Corp. Herm. O LSJ utiliza a edição crítica dos Hermetica de Walter Scott ao passo que o DGE tem preferência pela edição do Corpus Hermeticum de Arthur Darby Nock e André-Jean Festugière (N.-F.). Já Apostolides Sophocles utiliza o Hermetis Trismegisti Poemander de Gustav Parthey (Hermes Tr. Poem.). ${ }^{4}$

Tendo em conta a lista de frequência das palavras dos Hermetica Graca, no Index du Corpus Hermeticum (Delatte; Govaerts; Denooz, 1977, p. 209-75), sem considerar suas repetições, há aproximadamente 3.300 palavras nos textos que constituem o Corpus Hermeticum, os Stobaei Hermetica e os Fragmenta Hermetica, incluindo as ocorrências de palavras gregas no

\footnotetext{
${ }^{1}$ Isso também ocorre com o estudo de outros textos antigos, cf. Rossetti (2006, p. 252). Talvez o volume 9, intitulado Léxico da Filosofia Grega e Romana, em Reale (2008), possa ajudar nesse sentido.

${ }^{2}$ Lira (2018); Bertolini (1985).

${ }^{3}$ Lira (2021, p. 20).

${ }^{4}$ Liddell, Scott, Jones (1996, p. xxi, xxvi); Adrados ( $\left.s / d\right)$; Apostolides Sophocles (2011, p. xi).
} 
Asclepius Latinus, e excluindo empréstimos ou outros fenômenos de bilinguismo desse tratado. ${ }^{5}$ As 500 entradas ou lemas apresentadas neste Glossário são, predominantemente, palavras que incidem nas duas maiores coleções, a saber, no Corpus Hermeticum (tratados 1-18) e nos Stobaei Hermetica. Ademais, há referências de palavras que ocorrem nos Fragmenta Hermetica, no Asclepius, e nos textos herméticos de caráter mágico-astrológico, de iatromatemática (astrologia e medicina), ${ }^{6}$ como a Iatromathematica Hermetis Trismegisti ad Ammonem Aegyptium e o manuscrito Clarkianus Graecus 11 Oxoniensis.

Quanto ao texto grego da Iatromathematica Hermetis Trismegisti ad Ammonem Aegyptium, tanto o LSJ como Apostolides recorrem à edição de Julius L. Ideler que se encontra na sua coleção denominada Physici et Medici Graeci Minores, v. 1, de 1841. No que diz respeito ao Clarkianus Graecus 11 Oxoniensis, o DGE faz uso da edição de Jean-Pierre Mahé. ${ }^{7}$ Vale salientar que Mahé organizou recentemente um volume paralipômeno com vários textos e fragmentos herméticos de manuscritos diversos na mesma coleção dos textos de Nock-Festugière. ${ }^{8}$

As ocorrências dos textos herméticos juntas no LSJ, DGE e no Greek Lexicon de Apostolides podem chegar a mais de 500 palavras. Isso se dá porque Apostolides ainda referencia mais 6 palavras de outro tratado a Amon, também relacionado à iatromatemática ou exclusivamente à arte médica, denominado De morbis et infirmorum decubitu ex mathematica scientia (Apostolides Sophocles, 2011, p. 252, 469, 525, 573, 698, 777).

Por um lado, os textos herméticos são referenciados por fontes secundárias no contexto geral do estudo da Antiguidade e da língua grega antiga. Sendo assim, pode-se ter uma boa justificativa para ensejar uma pesquisa acerca dos textos herméticos na área de Estudos Clássicos. Por outro lado, é bem verdade que nem todas as palavras dos Hermetica Graca são figuradas no LSJ, DGE ou no Greek Lexicon de Apostolides. Ademais, Delatte, Govaerts e Denooz criticam, e com razão, o fato de que o LSJ não leva em conta muitos lemas e entradas pela forma que eles assumem no texto, o que garantiria um sentido bem exato. Outros lemas são tratados como se assumissem o mesmo sentido por terem certas correlações de formação. Essa é uma tendência de LSJ, como no caso das palavras $\mu$ oĩpa e

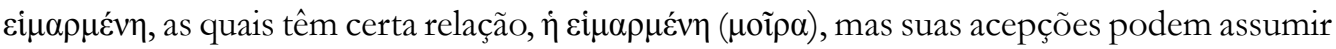
dimensões conceituais bem diferentes (Delatte, Govaerts Denooz, 1977, p. IX). Nota-se que, se, por um lado, um determinado léxico especializado nos Hermetica Graca certamente não abarca todos os lemas e lexemas desses textos, tendo de recorrer a um léxico mais amplo, como o LSJ; por outro lado, outrossim, é bem certo de que se encontraria uma certa limitação em relação aos Hermetica Graca no LSJ (McLean, 2014, p. 1).

Em todo caso, faz-se necessário levantar dados acerca do emprego e acepções de palavras gregas incidentes nos Hermetica Graca mencionadas em fontes secundárias, a saber, nos dicionários e léxicos gerais da língua grega. Em geral, trata-se de uma pesquisa

\footnotetext{
${ }^{5}$ Incidem 10-11 palavras gregas no Asclepius, cf. Lira (2018, p. 124-5).

${ }^{6}$ Sobre iatromatemática, medicina e astrologia no hermetismo, cf. Lira (2015, p. 32-3); Lira, Cyrous, Vieira (2016, v. 2, p. 103-17).

${ }^{7}$ Liddell, Scott, Jones (1996, p. xxi, xxvi); Adrados (s/d); Apostolides Sophocles (2011, p. xi).

${ }^{8}$ Nock; Festugière (2019).
} 
bibliográfica (lexical, vocabular, de dicionário e de glossário) que, de alguma forma, garante informações sobre acepções de palavras gregas empregadas nos Hermetica Graca, além das referências nas fontes secundárias. A finalidade é elencar todas as palavras gregas e suas acepções nos Hermetica Graca que LSJ, DGE ou o Greek Lexicon de Apostolides mencionaram (Eco, 1985, p. 37-8, 42-4; Marconi e Lakatos, 2010, p. 157-9, 166-8). Deve-se salientar que dados secundários, obtidos em dicionários e léxicos gerais de grego, não podem ser confundidos com documentos ou fontes primárias (pesquisa documental), como, por exemplo, os textos do Corp. Herm., dos Stobaei Hermetica e dos Fragmenta Hermetica (Eco, 1985, p. 37-8; Marconi e Lakatos, 2010, p. 159).

Poder-se-ia perguntar se o Glossário dos Hermetica Graca, apresentado aqui, teria potencial para expansão no que diz respeito à quantidade de lemas e acepções e à confirmação dessas acepções a partir de outras fontes secundárias. Para isso, pode-se recorrer aos índices dos livros de Dodd, Copenhaver e Festugière (Dodd, 1954, p. 251-255; Copenhaver, 2000, p. 261-9; Festugière, 2014, p. 1913-23). Trata-se de indices verborum gracorum que remetem a notas explicativas e a passagens que discutem, entre outros assuntos, o sentido das palavras no contexto dos tratados herméticos. Em geral, Dodd, Copenhaver e Festugière indicam não apenas os termos da Literatura Hermética, mas também de outros textos mencionados por eles. Em acréscimo, o Hellenistic and Biblical Greek de McLean apresenta uma seleção dos textos gregos do primeiro tratado do Corp. Herm., intercalados pelos vocabulários (McLean, 2014, p. 406-21). Essa é uma fonte que tem ajudado a expandir a gama de lemas e lexemas na atual pesquisa.

Outrossim, poder-se-ia argumentar que uma pesquisa bibliográfica desse porte seria uma mera repetição do que foi escrito sobre a Literatura Hermética, sua linguagem, termos técnicos etc. Como pesquisa bibliográfica, esse tipo de levantamento instrumental busca encontrar meios para definir e resolver um problema que se faz evidente e notório. Em outras palavras, o pesquisador pode compreender mais facilmente como empregar o instrumento e como manipulá-lo.

Qualquer pesquisa sobre tradução que envolva textos gregos precisa ter previamente um levantamento bibliográfico de ferramentas de tradução (Rossetti, 2006, p. 252). Faz-se necessário observar se existem obras que tratam do tema e do objeto analisado e estudado. Neste caso específico, trata-se de tradução de palavras do grego antigo para a língua portuguesa, especificamente daquelas que incidem nos Hermetica Graca. Os dicionários e léxicos, assim, dão estofo aos argumentos de tradução que resultará no produto final (Kahlmeyer-Mertens et al., 2009, p. 35).

Convém definir os objetivos da pesquisa, para que se julgue que documentação é mais adequada às finalidades, uma vez que qualquer uma das fontes pode ser inexata, distorcida ou errônea (Eco, 1985, p. 39; Marconi e Lakatos, 2010, p. 159). Isso pode ser percebido quando aquela fonte primária dos Hermetica apresenta conjecturas de lectio que não figuram nos códices, sendo apenas uma suposição do editor - o que pode interferir na escolha de texto crítico que um dicionário ou léxico faz para referenciar as ocorrências. 


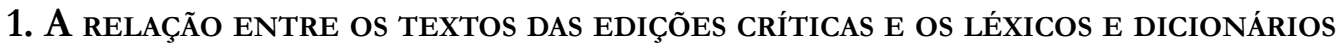

É importante comentar sobre os textos críticos dos Hermetica de Walter Scott, do Corpus Hermeticum de Arthur Darby Nock e André-Jean Festugière (N.-F.) e do Hermetis Trismegisti Poemander de Gustav Parthey (Herm. Tr. Poem.). Não obstante o surgimento das edições do texto grego do Corpus Hermeticum no séc. XVI, a primeira edição crítica (baseada em várias cópias manuscritas e edições) só se deu na metade do séc. XIX. O filólogo alemão Gustav Parthey publicou o seu Hermetis Trismegisti Poemander em 1854, compreendendo os tratados I a XIV do Corpus Hermeticum. Essa edição apresenta um texto grego com aparato crítico e uma tradução em latim à margem inferior. Pode-se dizer que se trata de uma primeira edição crítica do texto grego do Corpus Hermeticum (Lira, 2015, p. 84-5; Van den Kerchove, 2012, p. 7; Scott, 1985, v. 1, p. 43-4; Dodd, 1954, p. xiii.). ${ }^{9}$ No entanto, embora, no prefácio do Hermetis Trismegisti Poemander, Parthey diga que emprega como base para a construção do texto grego do Hermetis Trismegisti Poemander os manuscritos A (Laurentianus 71, 33) e B (Parisinus Graecus 1220), percebe-se que as leituras de um e de outro nem sempre são fidedignas, e o que sugere como A é B ou B ${ }^{2}$ (copista de B). É bem verdade que ele fez largamente uso das edições de Turnebus, Flussas e Patrizzi, principalmente do último (Lira, 2015, p. 84-5; Scott, 1985, v. 1, p. 24, 44; Dodd, 1954, p. xiii).

Se a edição de Parthey não for considerada a primeira edição crítica do texto grego do Corpus Hermeticum, ao menos ela terá contribuído de alguma forma para as edições críticas que aparecerão subsequentemente, ainda que, por não ter evidenciado as leituras manuscritológicas de forma acurada, seja possível que alguns pesquisadores tenham negligenciado sua edição. Parthey praticamente teve como fundamento a edição de Patrizzi (Lira, 2015, p. 84-5).

O filólogo Walter Scott (1855-1925) produziu uma obra extremamente densa em quatro volumes, chamada Hermetica: the ancient Greek and Latin writings which contain religious or philosophical teachings ascribed to Hermes, que foi inicialmente publicada entre $1924 \mathrm{e}$ 1936. Reitzenstein chegou a conhecer o primeiro volume dessa obra, empregando alguns comentários de Scott nos seus estudos em 1926. Os volumes dois e três dos Hermetica de Scott foram publicados em 1926. O quarto volume, que contém os Fragmenta, foi completado com as notas abundantes de A. S. Ferguson, já que Scott faleceu um ano depois (1925) de ser publicado o primeiro volume. Com a morte de Scott, o quarto volume demorou dez anos (de 1926 a 1936) até ser publicado por Ferguson com as notas dos Fragmenta e índices analíticos (Copenhaver, 2000, p. liii; Dodd, 2005, p. 11-2, n. 3; Lira, 2015, p. 86-7).

O primeiro volume é constituído de uma introdução geral aos Hermetica, comentários, notas e adendos sobre o mundo dos autores herméticos, datação dos tratados, crítica textual e datação dos manuscritos. Além disso, o primeiro volume apresenta integralmente os textos gregos do Corpus Hermeticum, dos Stobaei Excerpta Hermetica e dos Fragmenta, além do texto latino do Asclepius. Os textos gregos e o latino são devidamente acompanhados com um aparato crítico e a tradução paralela em inglês. Os outros volumes são notas interpretativas

\footnotetext{
${ }^{9}$ Parthey (1854).
} 
dos textos do Corpus Hermeticum, do Asclepius, dos Stobaei Excerpta Hermetica e dos Fragmenta. A coleção dos Hermetica é considerada uma obra de imensa contribuição para a pesquisa sobre o hermetismo e sobre a literatura hermética no que diz respeito à quantidade abundante de materiais de estudo contidos nesse trabalho. Não há como negar que, ao suscitar questões de ordem cronológica e problemas das fontes, baseando-se em relações literárias e respeitando as leis de evidências, as informações contidas na introdução dos Hermetica de Scott demonstram um teor acuradamente científico, acadêmico e sóbrio (Dodd, 1954, p. xiii; Copenhaver, 2000, p. liii; Dodd, 2005, p. 11-2, n. 3; Lira, 2015, p. 86-7).

Para proceder à crítica textual, Scott fez largo uso das leituras manuscritológicas publicadas por Richard Reitzenstein, além de utilizar as leituras das edições de Turnebus, Flussas, Patrizzi e Parthey. No que diz respeito aos manuscritos, os mais empregados por Scott são A, C (Vaticanus Graecus 237), M (Vaticanus Graecus 951), Q (Bodleianus 3388), R (Bodleianus 8827) e S (Bodleianus 3027) (Scott, 1985, v. 1, p. 23-4). No entanto, pelo fato de Scott ter se tornado obcecado pelo arquétipo dos manuscritos do Corpus Hermeticum, ele submeteu os textos dos tratados herméticos a uma construção hipercrítica, procedendo a muitas conjecturas arbitrárias no texto (interpolações, correções e transposições), o que resultou em desconfiança sobre sua leitura. Embora indique as variantes dos manuscritos e edições antigas (no apparatus criticus), e demonstre uma pesquisa exaustiva (com teor científicoacadêmico), prevalecem quase sempre as suas conjecturas, e não a lectio dos manuscritos (Dodd, 1954, p. xiii; Scott, 1985, v. 1, p. 24-6ss; Copenhaver, 2000, p. liii; Dodd, 2005, p. 11-2, n. 3; Lira, 2015, p. 87).

Várias conjecturas de Walter Scott podem ser consideradas corretas, mas há várias conjecturas arbitrárias, desnecessárias e incorretas. De qualquer maneira, a obra de Scott se tornou um clássico da pesquisa do hermetismo no que diz respeito à sua riqueza informativa nos comentários e nas notas explicativas, tornando-se, assim, um material indispensável e valioso à pesquisa (Dodd, 1954, p. xiii; Scott, 1985, v. 1, p. 24-6ss; Copenhaver, 2000, p. liii; Dodd, 2005, p. 11-12, n. 3; Lira, 2015, p. 87).

A edição crítica padrão do texto grego e latino dos escritos herméticos foi publicada por Arthur Darby Nock e André-Jean Festugière entre 1945-1954. Festugière procedeu à tradução francesa do Corpus Hermeticum, tendo recorrido ao texto grego e latino estabelecido por Arthur Darby Nock. Festugière e Nock foram grandes cooperadores e coautores da edição francesa do Corpus Hermeticum. Nock (1902-1963) era filólogo e historiador das religiões (Lira, 2015, p. 87-8). O Corpus Hermeticum de Nock-Festugière (também abreviado N.-F.) é dividido em quatro tomos, que compreendem o Corpus Hermeticum, o Asclepius, os Stobaei Excerpta Hermetica e os Fragmenta. Nock diz na introdução dessa obra que:

Nestes dois primeiros volumes, o texto [grego e latino] e o aparato, a introdução crítica ao Corpus Hermeticum e a introdução geral ao Asclepius são obra minha. A tradução, as notas sobre a tradução [francesa] e as introduções particulares de cada tratado são deveres de meu querido rev. pe. A. J. Festugière. Cada um de nós tem examinado em detalhe o trabalho do outro e conversado: a união de nossos dois 
nomes na página de título representa bem mais que uma colaboração puramente externa (tradução própria). ${ }^{10}$

Embora Nock e Festugière designem a coleção completa dos escritos herméticos de Corpus Hermeticum, apenas os dois primeiros tomos compreendem o Corpus Hermeticum e Asclepius propriamente, com paginação contínua entre o tomo 1 e 2, formando duas partes de um todo: o tomo 1 é constituído dos tratados I a XII (1 ${ }^{\text {a }}$ ed. em 1945; $2^{a}$ ed. em 1946); o tomo 2 é constituído dos tratados XIII-XVIII e Asclepius (1 ${ }^{\mathrm{a}}$ ed. em 1946). Festugière se ocupou da edição crítica e tradução dos tomos seguintes: tomo 3 - Stobeus I-XXII (1 $1^{\mathrm{a}}$ ed. em 1954); tomo 4 - Stobeus XXIII-XXIX (1 ${ }^{\mathrm{a}}$ ed. em 1954). ${ }^{11}$

Em geral, Nock foi responsável pelo texto crítico enquanto Festugière foi incumbido da tradução francesa, introduções a cada tratado e comentários. Sabe-se que Nock empregou 28 manuscritos diferentes e todas as edições impressas disponíveis do Corpus Hermeticum para sua edição crítica. Segundo ele, o trabalho de inventariação manuscritológica e das comparações textuais durou doze anos, tendo sido finalizado em 1938 (Lira, 2015, p. 88). A edição de Nock-Festugière ganhou notoriedade e credibilidade por ser um texto crítico cuidadosamente conservado de acordo com os manuscritos e sem a necessidade de conjecturas desnecessárias como as de Scott. Em 2005, a edição de Nock-Festugière foi publicada em italiano pela filósofa e classicista Ilaria Ramelli, em um único tomo, atualizando algumas informações e notas. Ramelli adicionou à coleção o texto copta do tratado do NHC VI.6 (De Ogdoade et Enneade ou o Discurso sobre a Ogdoada e a Enéada) com comentários seus e uma ampla atualização bibliográfica de pesquisa, além de uma introdução aos escritos coptas, indicando as novas orientações que os pesquisadores tomaram desde a descoberta de três textos herméticos na Biblioteca de Nag Hammadi. Ela também estabeleceu uma lista bibliográfica de pesquisa acerca dos escritos herméticos coptas e sobre o hermetismo filosófico nos últimos cinquenta anos (Dodd, 2005, p. 11-2, n. 3; Schiavone, 2006, p. 5, 30-1; Nock; Festugière, 2011, t. 1, p. IX, XI-II, LIV; Lira, 2015, p. 88-9). ${ }^{12}$

Pode-se inferir que, em geral, o LSJ e o Greek Lexicon de Apostolides fazem uso de textos críticos (de Scott e de Parthey) que podem conduzir a conjecturas, inexatidão, distorções ou concepções equivocadas, não obstante o que se mencionou anteriormente sobre sua validade. Como supramencionado, essas inconsistências do texto crítico podem interferir na escolha que um dicionário ou léxico faz para referenciar as ocorrências. Se o texto de Parthey é inconsistente, o texto de Scott, na verdade, é um verdadeiro quebra-cabeça

\footnotetext{
10 "Dans ces deux premiers volumes, le texte et l'apparat, l'introduction critique au Corpus Hermeticum et l'introduction générale à l'Asclépius sont mon œuvre. La traduction, les notes sous la traduction et les introductions particulières à chaque traité sont dues à mon cher collège le R. P. A. J. Festugière. Chacun de nous a examiné en détail le travail de l'autre et l'a discuté avec lui : l'union de nos deux noms sur la page de titre représente bien plus qu'une collaboration purement extérieure" (Nock; Festugière, 2011, t. 1, p. VIII).

${ }^{11}$ Nock; Festugière (2011).

${ }^{12}$ Cf. Nock; Festugière (2005).
} 
ou labirinto de conjecturas que tornam impraticável uma leitura corrente. Ademais, Scott coloca em dúvida as variadas lectiones, as quais podem ser qualquer coisa, menos "herméticas".

Em última análise, um procedimento de cotejamento entre as edições dos textos críticos de Parthey, Scott e N.-F. se faz necessário no que se refere às ocorrências de uma determinada lectio no LSJ, no DGE e no léxico de Apostolides. O procedimento de cotejamento também deve ser levado em consideração em relação às fontes secundárias. Elas podem evidenciar acepções diferentes para uma palavra em determinado contexto, podem, outrossim, assumir uma determinada lectio de um texto crítico ou podem confirmar uma ou várias acepções e lectiones.

Por fim, lidar com as ferramentas também pressupõe saber qual é a fonte utilizada pelo tradutor. Assim, quem quer que busque informações lexicais em LSJ ou mesmo no Hellenistic and Biblical Greek de McLean deverá estar ciente de que ele terá de consultar o texto crítico de Walter Scott.

\section{A definição de Glossário dos Hermetica Greca}

Este Glossário dos Hermetica Graca não pretende ser um index ou uma lista das palavras de todos os Hermetica Graca. A lista de palavras, como supramencionado, é estabelecida a partir das referências incidentes no LSJ, no DGE e no léxico de Apostolides. Não se trata de um dicionário que contém a língua geral nem tampouco se trata de um léxico com palavras de um único autor ou de uma mesma obra - inclusive, porque os autores herméticos são diversos (Miranda Poza, 2017, p. 32). O Glossário dos Hermetica Graca tem um aspecto diferente: compreende palavras com acepções diferentes, dúbias (dubio sensu), grafias divergentes (dubia lectio), vera lectio, falsa lectio, acepções que requerem alguma iniciação no próprio mundo do hermetismo. Ora são problemas manuscritológicos de transmissão, ora são problemas de uso mesmo. Quanto aos problemas manuscritológicos, coube aos editores estabelecer um texto crítico. Não obstante, o sentido que uma determinada palavra assume no contexto dos Hermetica Graca perde uma polissemia generalizante de um dicionário do grego ou um delimitador de um léxico exclusivo de determinado autor e de suas obras.

Também não se trata de estabelecer uma seleção de vocábulos da língua grega a partir de critérios externos, nem por questões exclusivamente de uso e origem, nem para estabelecer terminologias técnicas do hermetismo (Miranda Poza, 2017, p. 32), inclusive, porque os termos empregados nos Hermetica Graca também são de uso corrente na Antiguidade tardia, na filosofia e nas religiões mediterrâneas. Destarte, convém falar de um glossário, o qual lista e elenca palavras obscuras e que apresentam dificuldades interpretativas e hermenêuticas para o leitor ou tradutor (Miranda Poza, 2017, p. 32).

Então, essas palavras são apresentadas de forma simples, direta, em lista, seguindo uma ordem alfabética. São palavras sem qualquer explicação gramatical de classe, exceto quando é preciso dar sentido ao emprego em determinado contexto. Assim, incide apenas o significado, a indicação de oposição, de semelhança de sentido, de dubiedade. Lato sensu, este Glossário dos Hermetica Graca compreende substantivos, numerais substantivados, adjetivos, adjetivos substantivados, e verbos. Há advérbios no glossário, mas são raros. 
Obviamente, essas palavras são extraídas dos Hermetica Graca. O sentido das palavras é seguido de um contexto, amiúde, com referências de passagens em que são evidenciadas. As acepções são especificamente aquelas empregadas no contexto dos Hermetica Graca, prescindindo de qualquer acepção que não esteja relacionada aos textos herméticos. $\mathrm{O}$ fato de apresentar apenas uma referência não significa que aquela acepção só ocorra naquele contexto. Há palavras que incidem no Corpus Hermeticum e nos Stobaei Hermetica com o mesmo sentido. Quando a palavra apresenta uma acepção diferente, há sempre uma indicação referencial. O grego do Corpus Hermeticum, e dos tratados herméticos em geral, é aticizante. Por grego aticizante, deve-se compreender que se trata de um grego helenístico ou koinè que seguia os padrões literários do grego clássico ou ático dos autores do quarto e quinto séculos A.E.C. (McLean, 2014, p. 7). No entanto, a linguagem mística dos tratados herméticos é muito semelhante à linguagem do paganismo e do cristianismo do início da Era Comum. Essa linguagem é assaz tautológica, fazendo uso de termos técnicos da filosofia grega, lembrando ora a linguagem platônica, ora a estoica (Lira, 2021, p. 20).

Por fim, para o Glossário dos Hermetica Graca, é necessário um Conspectus Siglorum et Signorum, um conspecto de siglas, abreviaturas e sinais, os quais incidem nas descrições dos lemas. Eles indicam uma contextualização das incidências daquelas palavras em determinada passagem dos tratados dos Hermetica Greca.

\section{Conspectus Siglorum et Signorum}

= igual

$\neq$ diferente

$<=$ este sinal indica que uma palavra deriva ou é composta de outra.

$\dagger=$ a crux desperationis e o locus desperatus indicam a ininteligibilidade da palavra.

adv. = advérbio, adjunto adverbial

Apostolides = Greek Lexicon de Apostolides Sophocles

Ascl. = Asclepius Latinus

astrol. $=$ astrologia, linguagem astrológica

cf. = confira, compare

cod. $=$ códex, codd.$=$ códices

Corp. Herm. = Corpus Hermeticum

DGE $=$ Diccionario Griego-Español en linea

dist. $=$ distinto, diferente

dub. = dubio sensu, dubia lectio

f.l. = falsa lectio

Frag. Herm. $=$ Fragmenta Hermetica

Frag. Ox. = Fragmenta Hermetica do Clarkianus Graecus 11 Oxoniensis

Herm. ad Amm. = Iatromathematica Hermetis Trismegisti ad Ammonem Aegyptium

Herm. ap. Stob. $=$ Hermes Trismegistus apud Stobaeum

LSJ = A Greek-English Lexicon de Liddell-Scott-Jones

med. = medicina, médica 
metaf. = metafórico

N.-F. = texto crítico do Corpus Hermeticum estabelecido por Arthur Darby Nock e AndréJean Festugière.

NHC $=$ Nag Hammadi Codices (Códices de Nag Hammadi)

op. = oposto a

Parthey ou Hermes Tr.Poem. = texto crítico do Hermetis Trismegisti Poemander de Gustav Parthey pl. = plural

s.v.l. = si vera lectio

Scott $=$ texto crítico dos Hermetica de Walter Scott

Stob. Herm. = Stobaei Hermetica Excerpta

v. pas. = voz passiva

v.l. = vera lectio

\section{Glossário dos Hermetica GrECA ${ }^{13}$}

\section{A}

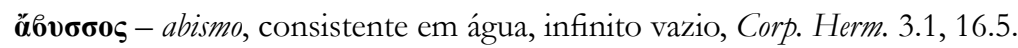

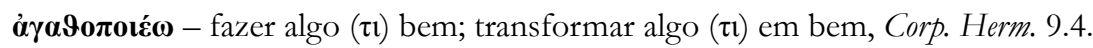

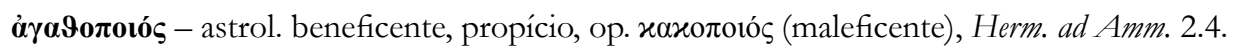

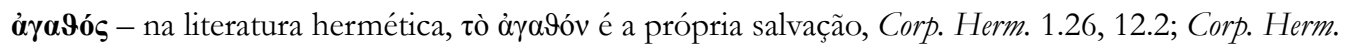
2.16-17.

$\dot{\boldsymbol{\alpha}} \boldsymbol{\gamma} \boldsymbol{\alpha} \boldsymbol{\pi \eta \tau} \boldsymbol{\tau} \boldsymbol{x} \tilde{\boldsymbol{\omega}} \boldsymbol{\varsigma}-\mathrm{adv}$. amorosamente, afetivamente, Corp. Herm. 1.22.

ă $\gamma \gamma \boldsymbol{\varepsilon} \mathbf{\lambda} \mathbf{o} \boldsymbol{\varsigma}$ - ser semidivino, Herm. ap. Stob. 1.49.45.

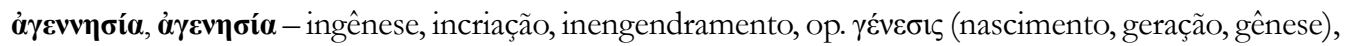
Stob. Herm. 9, Herm. ap. Stob. 1.11.2.

à $\gamma \mathbf{v} \omega \boldsymbol{\sigma} \boldsymbol{i} \boldsymbol{\alpha}$ - op. $\gamma \boldsymbol{\gamma} \tilde{\sigma} \sigma \mathrm{\iota}$ (gnose, conhecimento), ignorância; impossibilidade; incerteza, insegurança de conhecer as coisas divinas, Corp. Herm. 1.27.

ơ $\gamma \chi \omega$ - estrangular, pressionar, Corp. Herm. 10.24, 7.3.

ă $\boldsymbol{\delta} \boldsymbol{\varepsilon} \boldsymbol{\varkappa} \mathbf{c} \boldsymbol{\varsigma}$ - não receptivo, incapaz de, Herm. ap. Stob. 3.11.31.

$\grave{\boldsymbol{\alpha}} \boldsymbol{\delta} \boldsymbol{\varepsilon} \boldsymbol{\lambda} \varphi \boldsymbol{\eta}$ - em genealogia abstrata, irmã, Corp. Herm. 9.1 .

$\boldsymbol{\alpha} \boldsymbol{\delta} \boldsymbol{\delta} \boldsymbol{\alpha} \boldsymbol{x} \boldsymbol{\omega} \boldsymbol{\lambda} \boldsymbol{v} \tau \boldsymbol{\omega} \boldsymbol{\varsigma}$ - livremente, sem travas, sem impedimentos, Stob. Herm. 25.10, Herm. ap. Stob. 1.49.68.

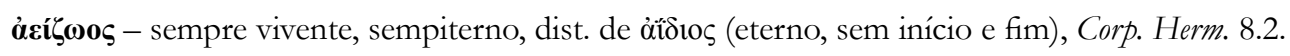

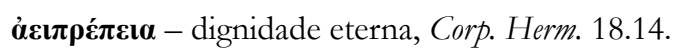

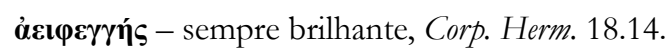

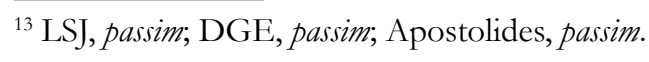




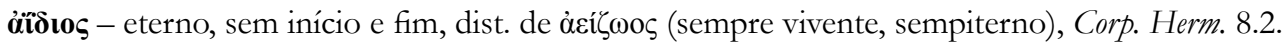

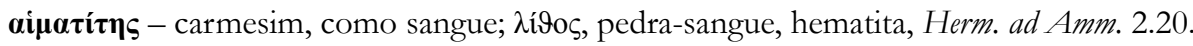

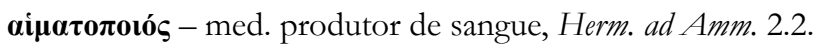

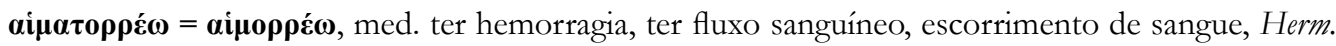
ad Amm.3.37.

$\boldsymbol{\alpha} \mathbf{i} \omega \mathbf{v}$ - aion, eon; eternidade, espaço de tempo, longo espaço de tempo, op. $\chi \rho o ́ v o \varsigma$ (tempo cronológico); Aî́v, personificado, Corp. Herm. 11 etc.; título de seres divinos.

$\dot{\boldsymbol{\alpha}} \boldsymbol{\varkappa} \mathbf{\lambda} \boldsymbol{\lambda} \boldsymbol{\lambda} \boldsymbol{\eta} \boldsymbol{\tau} \mathbf{i}$ - sem cumprimento, sem adesão, sem união, Herm. ap. Stob. 1.49.68, Stob. Herm. 25.10, 13.

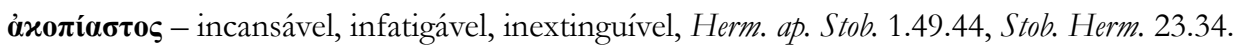

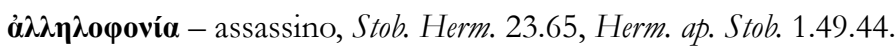

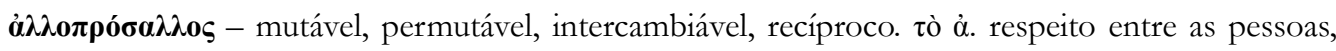
respeito mútuo, Corp. Herm. 18.14.

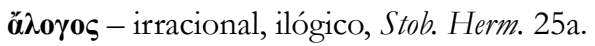

ג்

ג’ $\boldsymbol{\mu \varepsilon 9 o ́ \delta \varepsilon v \tau o \varsigma ~ - ~ q u e ~ n a ̃ o ~ p o d e ~ s e r ~ d e s v i a d o , ~ r e t o , ~ S t o b . ~ H e r m . ~ 2 3 . 6 2 , ~ H e r m . ~ a p . ~ S t o b . ~ 1 . 4 9 . 4 4 . ~}$

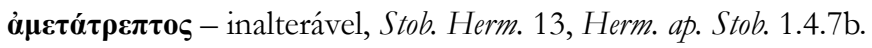

ג̆ $\boldsymbol{\mu} \boldsymbol{\gamma} \boldsymbol{\eta}$ s - sem mistura, sem mescla, puro, Herm. ap.Stob. 1.49.68, Stob. Herm. 25.10.

à $\boldsymbol{\mu о \rho \varphi} \boldsymbol{\alpha} \boldsymbol{\alpha}$ - carência de forma, amorfia, Herm. ap. Stob. 1.11.2.

ö $\mu \omega \mu \boldsymbol{\mu}$ - irrepreensível, intocado, sem mancha, sem mácula, imaculado, Stob. Herm. 11.2.29.

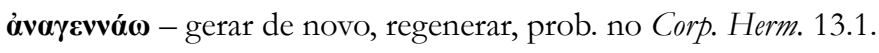

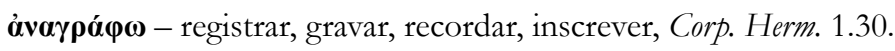

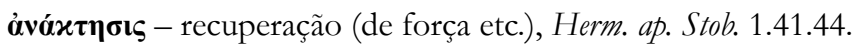

$\grave{\alpha} \mathbf{v} \boldsymbol{\alpha} \boldsymbol{\pi} \boldsymbol{\varepsilon} \boldsymbol{\mu} \boldsymbol{\pi} \boldsymbol{\omega}$ - enviar (jogar) para cima; atribuir algo a alguém, Corp. Herm. 18.12.

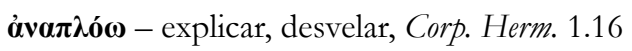

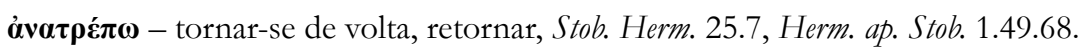

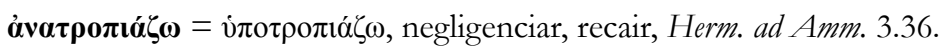

¿̀v $\boldsymbol{\alpha} \chi \boldsymbol{\alpha} \boldsymbol{\lambda} \boldsymbol{\alpha} \boldsymbol{\omega} \boldsymbol{~ - ~ r e l a x a r , ~ s o l t a r - s e , ~ H e r m . ~ a d ~ A m m . ~ 2 . 1 4 , ~ 3 . 2 . ~}$

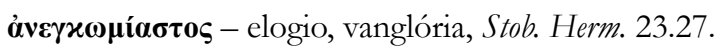

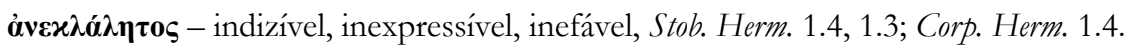

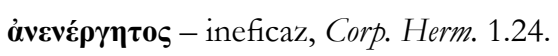

àve $\boldsymbol{\pi} \mathbf{i} \gamma \mathbf{v} \boldsymbol{\omega} \boldsymbol{\sigma} \boldsymbol{\tau} \mathbf{o}$ - não distintamente conhecido, irreconhecível, Herm. ap. Stob. 1.41.44.

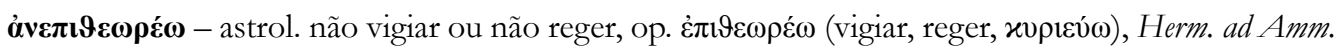
3.35 .

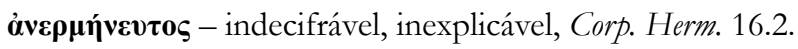

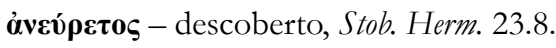




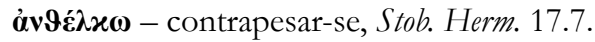

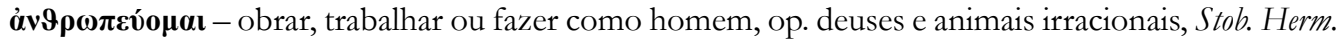
25.8, Herm. ap. Stob. 1.41.68.

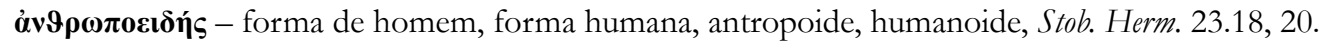

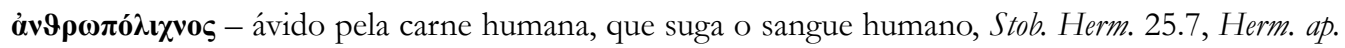
Stob. 1.41.68.

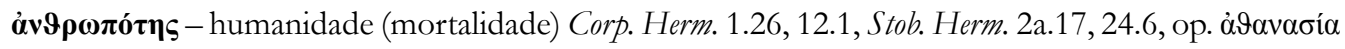
(imortalidade).

àvóntos - insensato, Corp. Herm. 1.23; não cultivado, alheio à filosofia, Corp. Herm. 6.3.

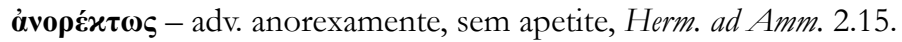

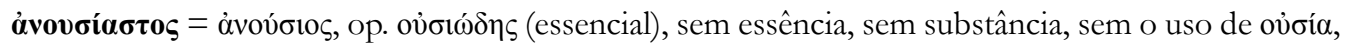
insubstancial, Corp. Herm. 2.5.

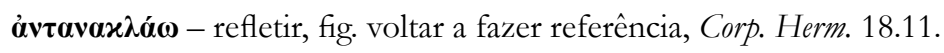

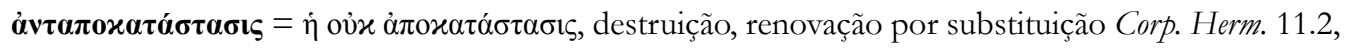
posição oposta à ả $\pi 0 x \alpha \tau \alpha ́ \sigma \tau \alpha \sigma ı \zeta$ (revolução, reconstituição, restituição, restauração), sendo ambas

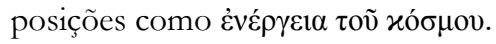

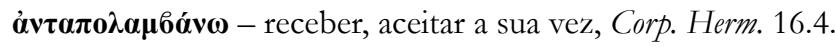

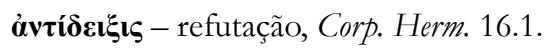

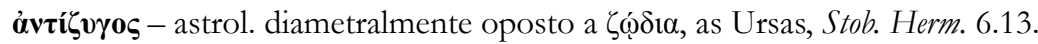

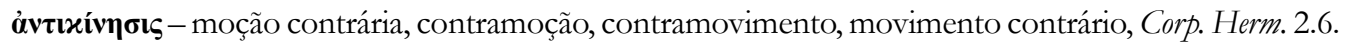
$\dot{\boldsymbol{\alpha}} \boldsymbol{v} \boldsymbol{\tau} \mathbf{\imath} \boldsymbol{\pi} \boldsymbol{\alpha} \boldsymbol{\alpha} \boldsymbol{\alpha} \boldsymbol{\delta} \boldsymbol{\delta} \boldsymbol{\delta} \boldsymbol{\omega} \boldsymbol{\mu} \mathbf{\imath}$ - suceder-se alternadamente, Stob. Herm. 23.50

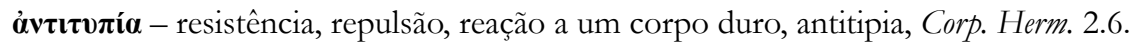

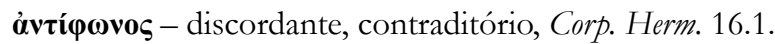

övтроv - fig. o interior da esfera, Corp. Herm. 8.3.

$\dot{\boldsymbol{\alpha}} \boldsymbol{v} \boldsymbol{\tau} \boldsymbol{\omega} \boldsymbol{\pi} \boldsymbol{\varepsilon} \omega=\dot{\alpha} \nu \tau \mathrm{\sigma} \phi \vartheta \alpha \lambda \mu \dot{\varepsilon} \omega$, olhar cara a cara, encarar, Corp. Herm. 1.7.

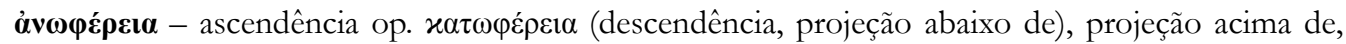
Corp. Herm. 16.8.3.

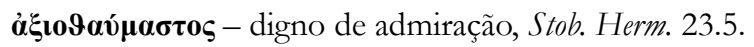

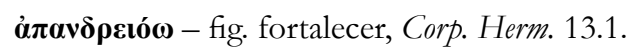

à $\boldsymbol{\pi} \boldsymbol{\alpha} \mathbf{\rho} \boldsymbol{\rho} \boldsymbol{\omega} \boldsymbol{\pi} \boldsymbol{i} \boldsymbol{\alpha}$ - misantropia, Stob. Herm. 26.7.

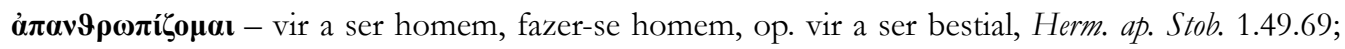
Stob. Herm. 26.20.

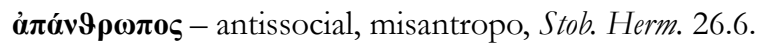

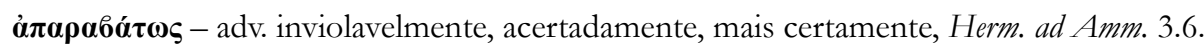

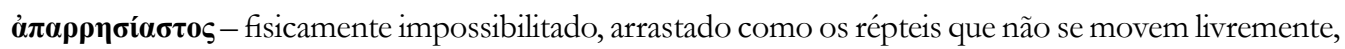
que não age livremente, qualidade dos répteis, Stob. Herm. 26.22, Herm. ap. Stob. 1.49.69. 


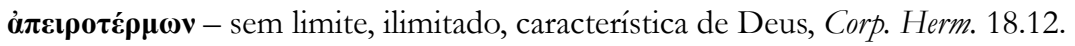

à $\boldsymbol{\pi} \boldsymbol{\varepsilon} \boldsymbol{\rho} \boldsymbol{\rho} \boldsymbol{v}$ - infinito, ilimitado, vasto, Stob. Herm. 29.

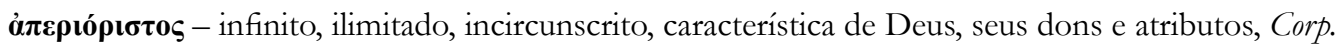
Herm. 1.1, 11.18.

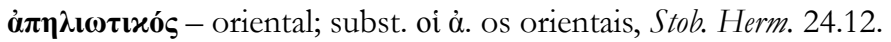

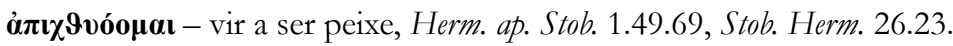

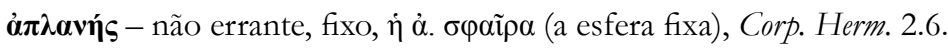

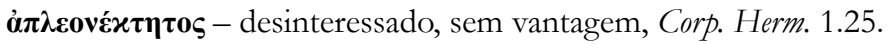

$\dot{\boldsymbol{\alpha}} \boldsymbol{\pi} \boldsymbol{\lambda} \mathbf{o} \boldsymbol{\omega}$ - abrir as mãos, as asas, Stob. Herm. 23.52.

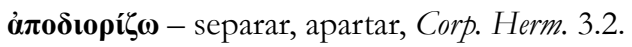

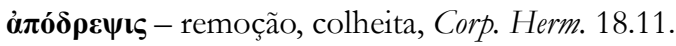

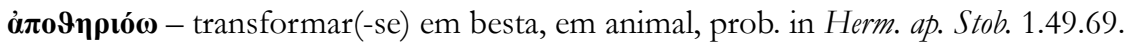

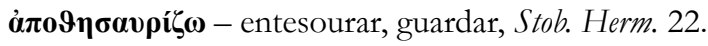

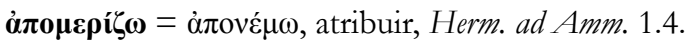

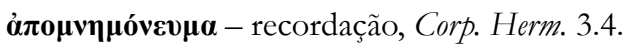

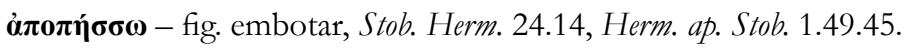

йлолоเє́( - desfazer, Corp. Herm. 9.6.

à $\boldsymbol{\pi} \mathbf{\rho} \boldsymbol{v} \varepsilon \mathbf{\omega} \boldsymbol{\omega}$ - v. pas. converter-se (transforma-se) em pássaro, Stob. Herm. 26.19, Herm. ap. Stob. 1.49.69.

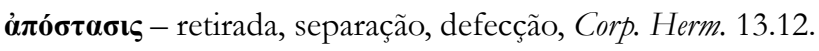

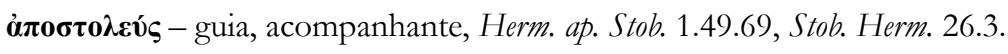

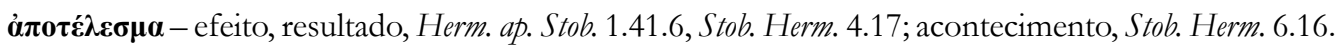

$\dot{\boldsymbol{\alpha}} \boldsymbol{\pi} \boldsymbol{\omega} \boldsymbol{\lambda} \mathbf{\varepsilon} \boldsymbol{\alpha}$ - destruição, morte, Corp. Herm. 8.4, 11.14, 12.16.

ă $\boldsymbol{\rho} \boldsymbol{\alpha}$ - conclusão de um silogismo, Herm. ap. Stob. 3.11.31.

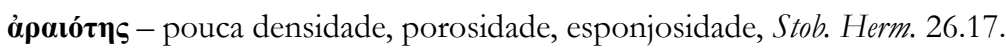

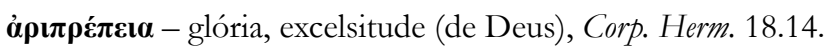

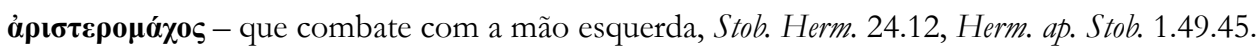

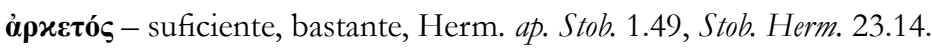

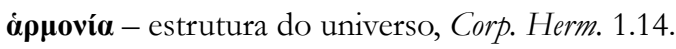

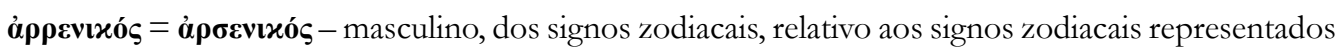

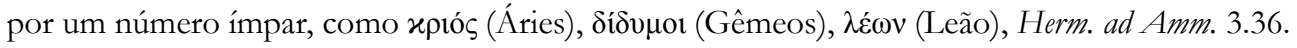

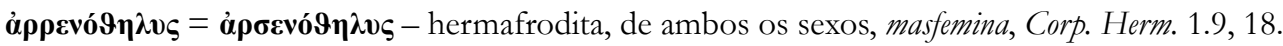

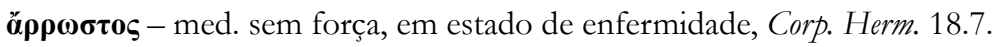

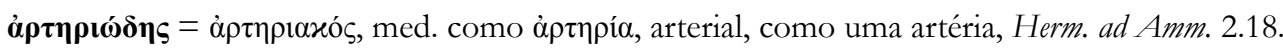

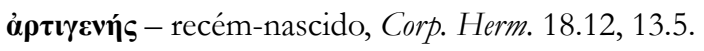




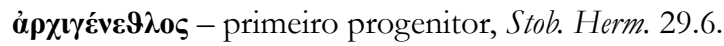

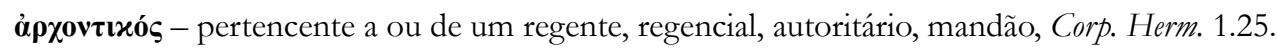

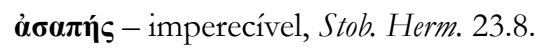

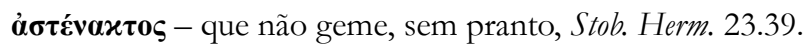

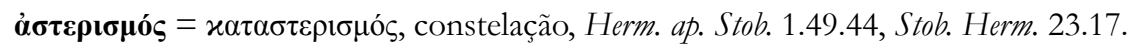

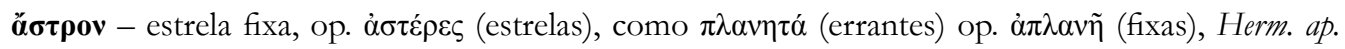
Stob. 1.21.9, Stob. Herm. 6.17.

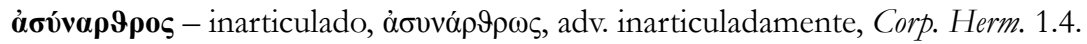

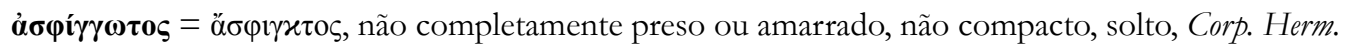
13.6 codd.

$\grave{\alpha} \tau \varepsilon \lambda \eta ́ s$ - sem fim, infindo, infinito, Corp. Herm. 4.8.

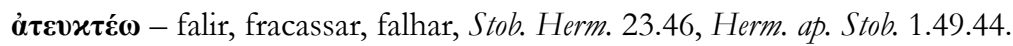

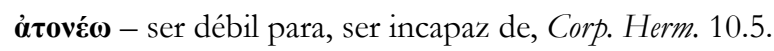

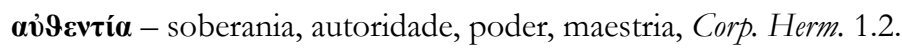

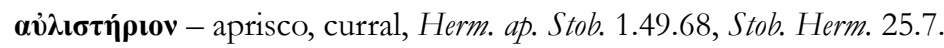

$\boldsymbol{\alpha} \boldsymbol{v} \xi \boldsymbol{\eta} \tau \mathbf{c} \varsigma$ - aumentável, aumentado, Corp. Herm. 4.11.

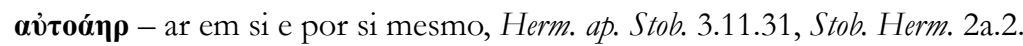

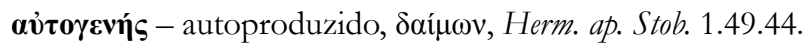

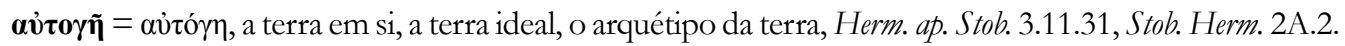

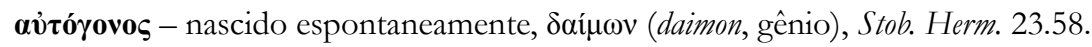

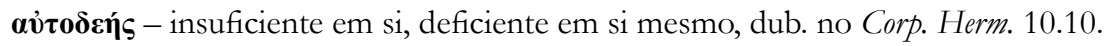

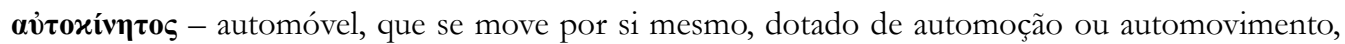
Stob. Herm. 16.1.3, Stob. Herm. 30.1.4.

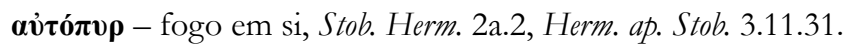

$\boldsymbol{\alpha} \boldsymbol{v} \tau \mathbf{0} \boldsymbol{\delta} \boldsymbol{\delta} \boldsymbol{~ - ~ a ́ g u a ~ p u r a , ~ a ~ a ́ g u a ~ e m ~ s i , ~ S t o b . ~ H e r m . ~ 2 a . 2 , ~ H e r m . ~ a p . ~ S t o b . ~ 3 . 1 1 . 3 1 . ~}$

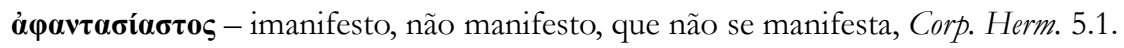

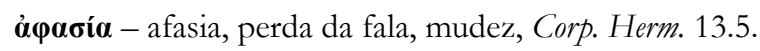

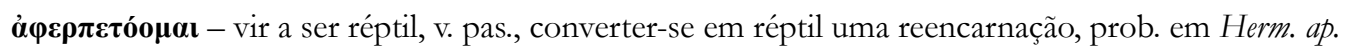
Stob. 1.49.69, Stob. Herm. 26.22.

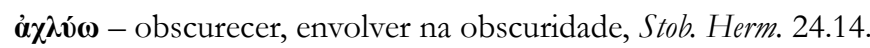

à $\chi \boldsymbol{\omega} \boldsymbol{\rho} \eta \boldsymbol{\tau o s}$ - incapaz de conter ou abarcar, Corp. Herm. 2.14. 


\section{B}

$\boldsymbol{\beta} \boldsymbol{\alpha} \lambda \lambda \boldsymbol{\omega}$ - pôr, Corp. Herm. 6.4.

$\boldsymbol{\beta} \boldsymbol{\alpha} \boldsymbol{\pi} \boldsymbol{\tau} \boldsymbol{\zeta} \boldsymbol{\zeta} \boldsymbol{\omega}$ - misturar (na cratera); embeber(-se) de, Corp. Herm. 4.4; encarnar, Corp. Herm. 12.2; estar sumido em, Stob. Herm. 25.8. ${ }^{14}$

$\boldsymbol{\beta} \boldsymbol{\alpha} \boldsymbol{\pi} \boldsymbol{\tau} \mathbf{\boldsymbol { \sigma }} \boldsymbol{\mu} \boldsymbol{o ́} \varsigma$ - fig. encarnação, Stob. Herm. 25.8.

$\boldsymbol{\beta} \boldsymbol{\alpha} \boldsymbol{\rho} \boldsymbol{\pi} \boldsymbol{\varepsilon} \boldsymbol{\psi} \boldsymbol{i} \boldsymbol{\alpha} \boldsymbol{\alpha}$ - indigestão, dificuldade para digerir, Herm. ad Amm. 3.50.

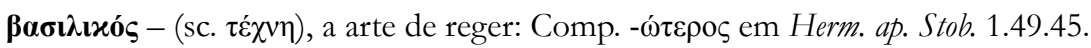

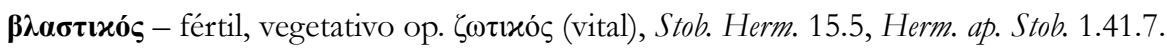

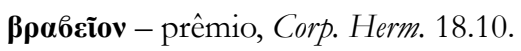

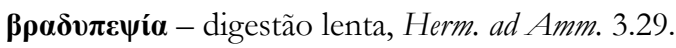

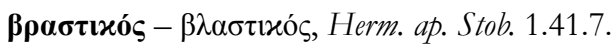

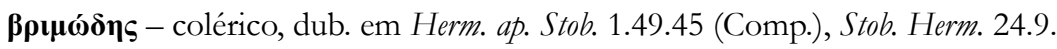

\section{$\Gamma$}

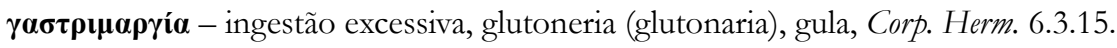

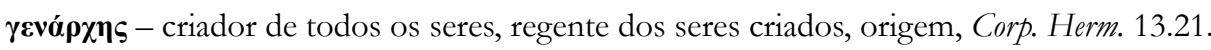

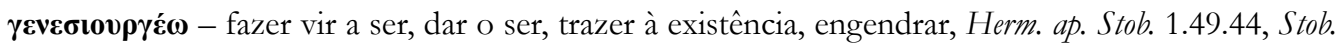
Herm. 23.15.

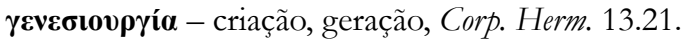

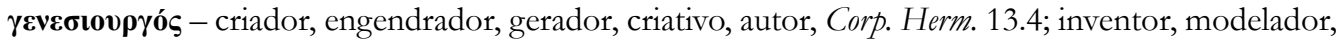
Stob. Herm. 23.44, Herm. ap. Stob. 1.49.44.

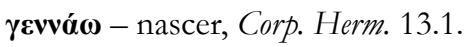

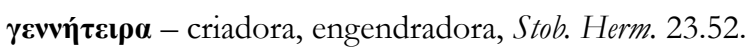

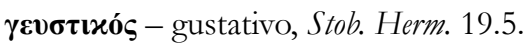

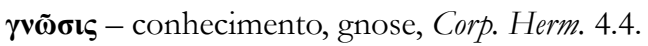

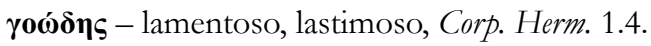

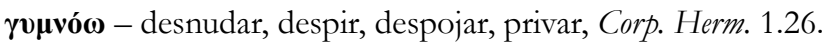

\footnotetext{
${ }^{14}$ Apostolides dá um sentido incorreto a essa acepção. Ele usa com sentido de "mergulhar", "afundar em”. Na segunda ocorrência do verbo $\beta \alpha \pi \tau i \zeta \omega$, no Corp. Herm. 4.4, há um genitivo partitivo que não permite outra acepção além de embeber(-se) de, embriagar(-se) de. O termo $\beta \alpha \pi \tau$ tı $\mu$ ó (encarnação) se encontra no livro do Korè Kosmou (Stob. Herm. 25.8). Em todo caso, esse termo não é empregado

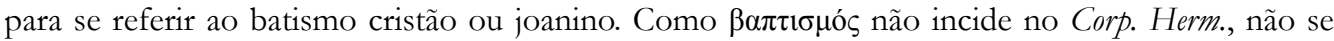
pode confrontar outras acepções. No entanto, a palavra $\beta \alpha \pi \tau i \zeta \omega$ também ocorre no Corp. Herm. 12.2, além do Corp. Herm. 4, com a acepção de encarnar, relacionando-se à acepção figurada da palavra

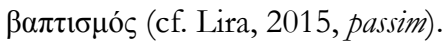




\section{$\Delta$}

$\boldsymbol{\delta} \boldsymbol{\alpha} \boldsymbol{\delta} \boldsymbol{\alpha} \boldsymbol{\lambda} \mathbf{0 v} \boldsymbol{\rho} \gamma \mathbf{i} \boldsymbol{\alpha}$ - arte de esculpir, trabalho curioso, Corp. Herm. 3.3.

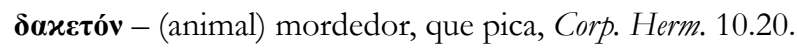

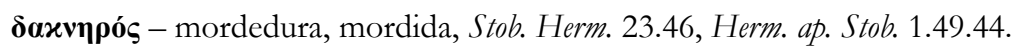

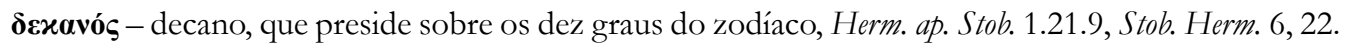

$\boldsymbol{\delta} \boldsymbol{\varepsilon} \boldsymbol{\sigma} \boldsymbol{\pi} \mathbf{\zeta} \boldsymbol{\omega}$ - na linguagem astrológica, reger sobre, Herm. ad Amm. 1.7.

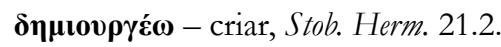

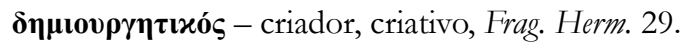

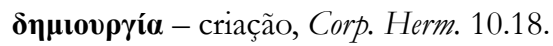

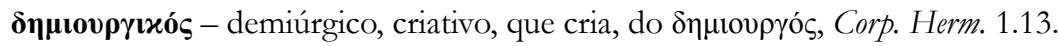

$\boldsymbol{\delta} \boldsymbol{\eta} \boldsymbol{\mu \iota 0 v \rho} \gamma \mathbf{o} \varsigma$ - demiurgo, criador, criativo, formativo, criador e governador do universo, ser subordinado, Corp. Herm. 1.9, 13.

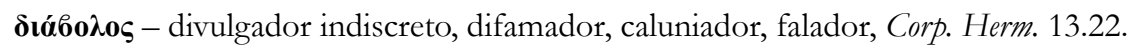

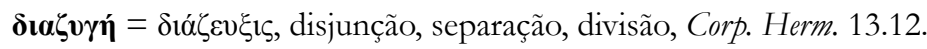

$\boldsymbol{\delta} \mathbf{i} \boldsymbol{\alpha} \zeta \boldsymbol{\omega} \boldsymbol{\mu \alpha}$ - estrato da atmosfera, camada, zona, nível, Herm. ap. Stob. 1.49.69, Stob. Herm. 26.8.

$\boldsymbol{\delta} \boldsymbol{\mathbf { \alpha }} \boldsymbol{x} \boldsymbol{\rho} \boldsymbol{\alpha} \boldsymbol{\tau} \boldsymbol{\varepsilon} \boldsymbol{\omega}$ - segurar de forma rápida e ajustada, controlar, Herm. ap. Stob. 1.15.16.

$\boldsymbol{\delta} \mathbf{\alpha} \boldsymbol{\mu} \boldsymbol{\varepsilon} \boldsymbol{\tau} \boldsymbol{\rho} \boldsymbol{\varepsilon} \boldsymbol{\omega}$ - ser diametralmente oposto, Herm. ad Amm. 2.12.

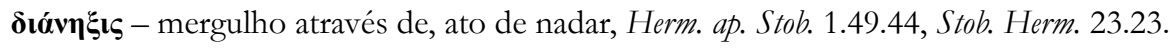

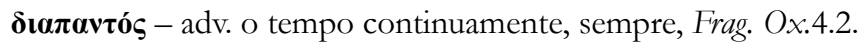

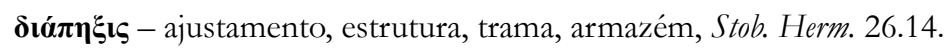

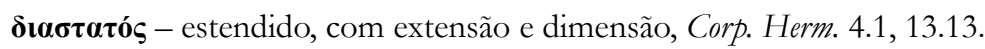

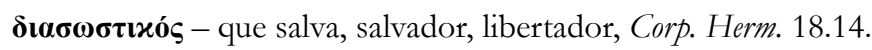

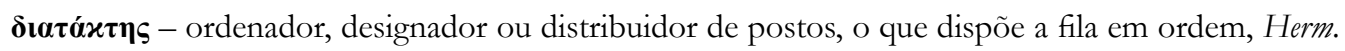
ap. Stob. 1.49.69, Stob. Herm. 26.3.

$\boldsymbol{\delta} \boldsymbol{\alpha} \tau \boldsymbol{\imath} \boldsymbol{\varkappa} \boldsymbol{\omega}$ - fundir-se, derreter-se, dissolver-se, aguar-se, liquefazer-se, Stob. Herm. 23.15.

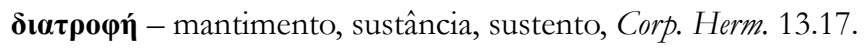

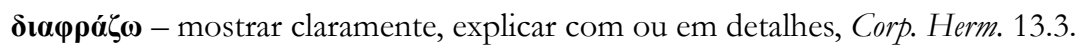

$\boldsymbol{\delta} \mathbf{\imath} \boldsymbol{\chi} \boldsymbol{\omega} \boldsymbol{\omega} \mathbf{\boldsymbol { i }} \boldsymbol{\zeta} \boldsymbol{\omega}$ - separar, produzir o procedimento por separação, Corp. Herm. 1.11.

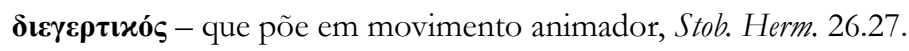

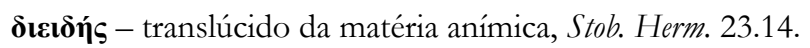

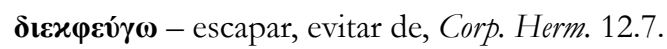

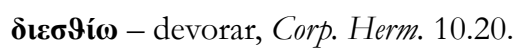

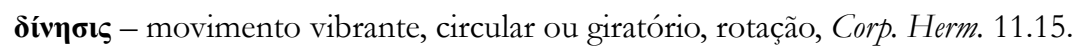

$\boldsymbol{\delta} \mathbf{\iota} \varkappa \boldsymbol{\eta} \boldsymbol{\eta} \boldsymbol{\varsigma}$ - astrol. dioceta, controlador, organizador, governador, regente, dos sete planetas ou astros, Corp. Herm. 1.9. 


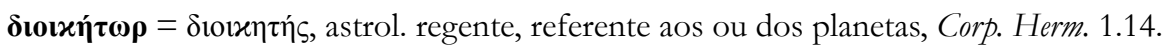

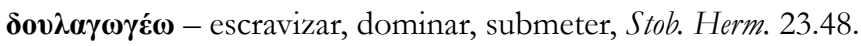

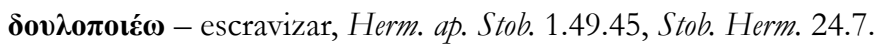

$\boldsymbol{\delta} \boldsymbol{\rho} \boldsymbol{\alpha} \boldsymbol{\xi}$ - punho, mão fechada, cerrada, Stob. Herm. 23.52, Herm. ap. Stob. 1.49.44.

$\boldsymbol{\delta} \boldsymbol{\rho} \boldsymbol{\mu} \boldsymbol{\eta} \boldsymbol{\mu \alpha}$ - astrol. curso (cíclico, dos planetas), Corp. Herm. 3.3.

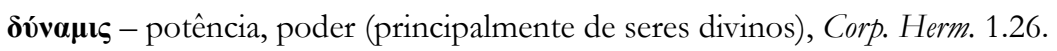

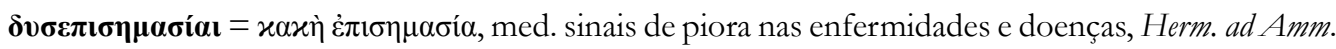
3.34 .

$\boldsymbol{\delta} \boldsymbol{v} \boldsymbol{\pi} \boldsymbol{\pi} \boldsymbol{\boldsymbol { \sigma } \tau \boldsymbol { \varepsilon }} \boldsymbol{\omega}$ - desconfiar, não crer, não se desejar convencer, Corp. Herm. 4.9.

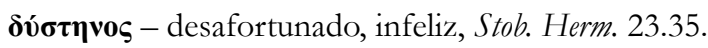

$\boldsymbol{\delta} \boldsymbol{\omega} \boldsymbol{\delta} \boldsymbol{\varepsilon} \boldsymbol{x} \boldsymbol{\varsigma} \varsigma$ - década, as dez potências, Corp. Herm.13.10.

\section{E}

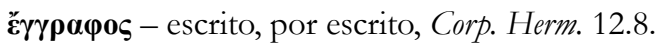

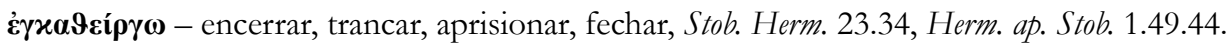

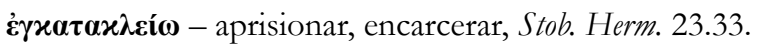

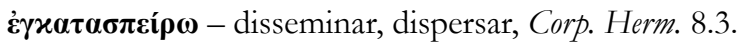

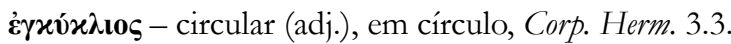

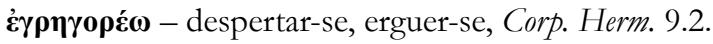

ह̊ $\boldsymbol{\delta} \boldsymbol{\alpha} \boldsymbol{\sigma} \boldsymbol{\mu} \boldsymbol{\alpha}$ - suporte, fundamento, base, Corp. Herm. 13.9.

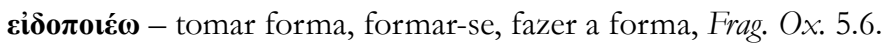

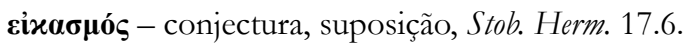

$\boldsymbol{\varepsilon} \mathbf{i} \lambda \boldsymbol{\varepsilon} \boldsymbol{\varepsilon}, \boldsymbol{\varepsilon} \mathbf{i} \lambda \omega$ - rodar, girar, Stob. Herm. 7.1, Herm. ap. Stob. 1.3.52.

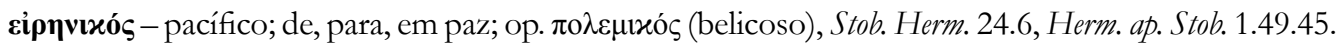

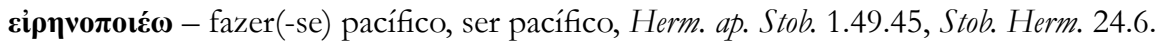

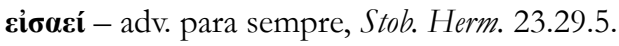

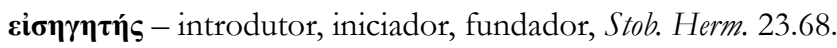

ยйболтроv - espelho, Corp. Herm. 17.2.

غ̇xooó́ - expulsar a gritos, Stob. Herm. 23.42.

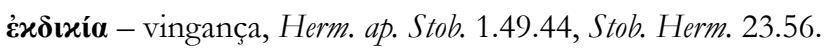

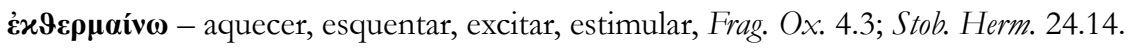

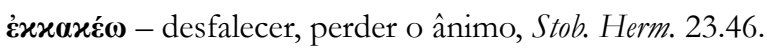

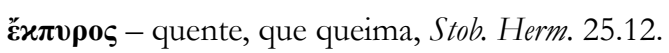

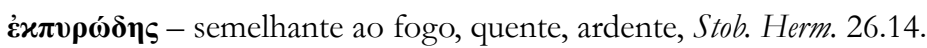


$\dot{\varepsilon} \boldsymbol{x} \boldsymbol{\tau} \boldsymbol{\varepsilon} \chi \boldsymbol{\alpha}$ - sair (fora), desviar-se (do tema), digredir, Corp. Herm. 1.16.

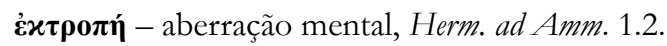

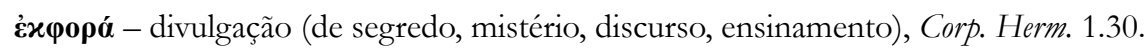

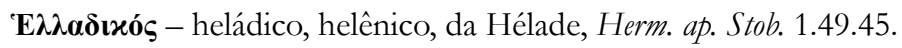

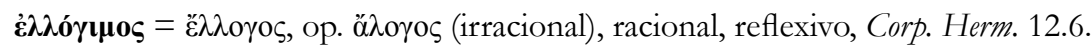

$\grave{\varepsilon} \boldsymbol{\mu} \boldsymbol{\pi} \boldsymbol{\alpha} 9 \mathbf{\eta} \boldsymbol{\varsigma}$ - med. passível, capaz de sentir, apaixonado, empático, doente, Herm. ad Amm. 3.30.

$\ddot{\boldsymbol{\varepsilon}} \boldsymbol{\mu} \boldsymbol{\pi} \boldsymbol{\alpha} \varsigma$ - turvo, barroso, barrento, barroso, Frag. Herm. 31.

$\dot{\varepsilon} \boldsymbol{\mu} \varphi \rho \boldsymbol{\alpha} \boldsymbol{\sigma} \boldsymbol{\sigma} \boldsymbol{\omega}$ - impedir, obstaculizar, Corp. Herm. 13.6.

$\dot{\varepsilon} \boldsymbol{\mu} \psi \mathbf{v} \chi \omega \sigma \mathbf{s}$ - processo pelo qual a alma entra no corpo, incorporação da alma, dotação de alma (vida), animação, Stob. Herm. 26.

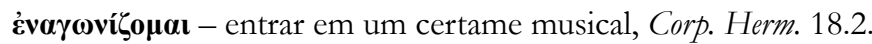

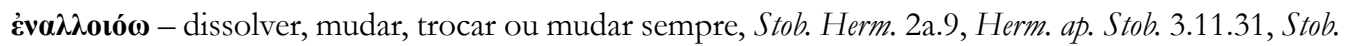
Herm. 11.2.34.

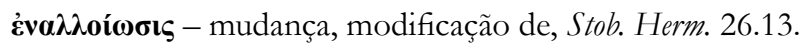

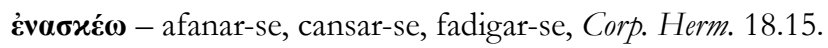

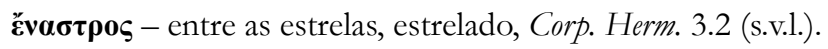

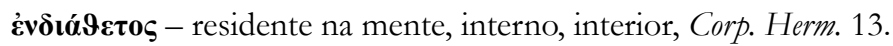

غ̇voı́ó

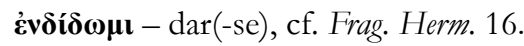

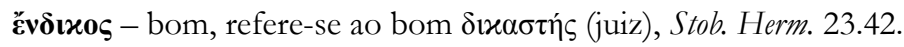

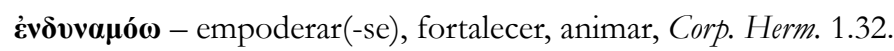

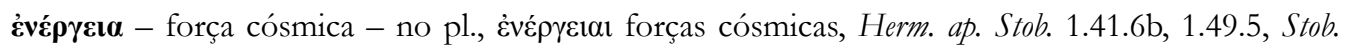
Herm. 4.6.

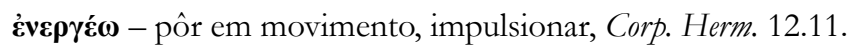

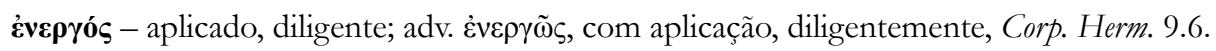

$\dot{\boldsymbol{\varepsilon}} \mathbf{v} \boldsymbol{9} \boldsymbol{\alpha} \boldsymbol{\delta} \boldsymbol{\varepsilon}$ - daqui, de cá, deste mundo, em oposição ao mundo ideal, Corp. Herm. 6.3.

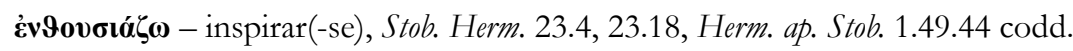

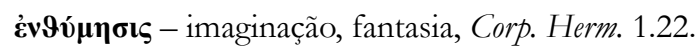

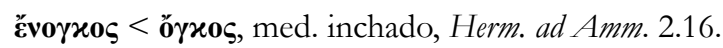

Ěvoıxos - residente, inquilino, arrendatário, Corp. Herm. 7.2.

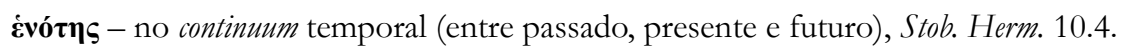

غ̇vó - unir, unificar, Stob. Herm. 20.7.

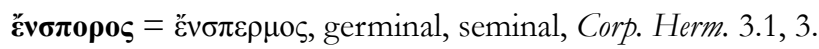

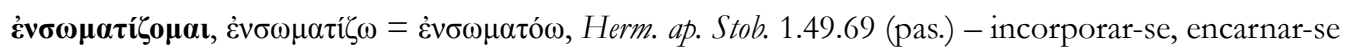

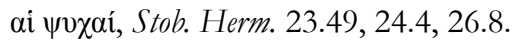




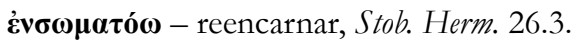

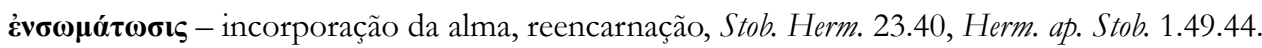

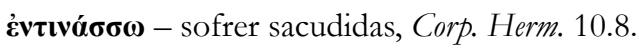

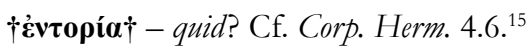

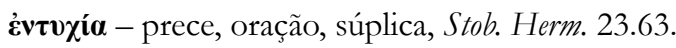

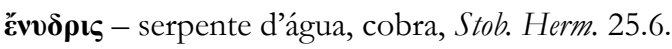

$\dot{\varepsilon} \mathbf{v} \omega \tau \boldsymbol{\tau} \mathbf{x} \boldsymbol{o ́} \varsigma$ - unificador, que procura a união ou tem a virtude e a qualidade de unir, Corp. Herm. 10.23; que une, que é capaz de congregar e alunar, Stob. Herm. 26.16.

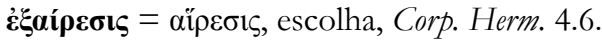

$\grave{\mathbf{\varepsilon}} \xi \boldsymbol{\alpha} \lambda \boldsymbol{\lambda} \boldsymbol{\alpha} \gamma \boldsymbol{\eta} \mathbf{\eta}$ - variedade de assuntos ref. às regiões celestes, Stob. Herm. 26.4.

$\dot{\boldsymbol{\varepsilon}} \boldsymbol{\xi} \boldsymbol{\alpha} \boldsymbol{\tau} \boldsymbol{\mu} \boldsymbol{\zeta} \boldsymbol{\zeta} \boldsymbol{\omega}$ - evaporar-se, Stob. Herm. 23.16.

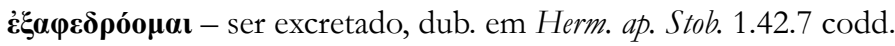

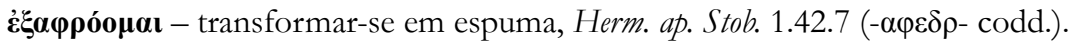

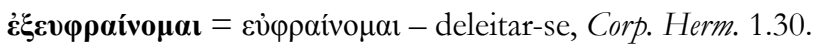

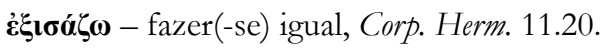

غ̇лєєброи́ - influxo, Corp. Herm. 10.4.

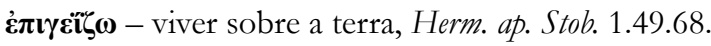

$\dot{\varepsilon} \boldsymbol{\pi} \mathbf{\imath} \boldsymbol{\varepsilon} \boldsymbol{\varepsilon} \boldsymbol{\lambda} \boldsymbol{\alpha} \omega$ - metaf. brilho sobre a superfície, Herm. ap. Stob. 1.49.44.

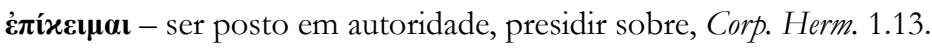

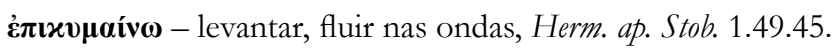

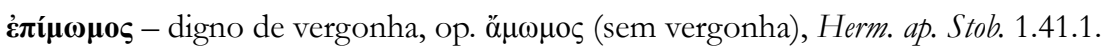

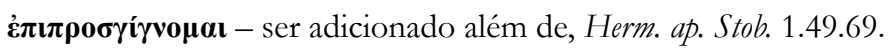

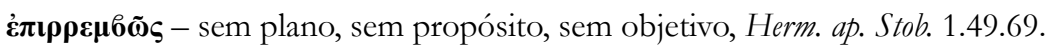

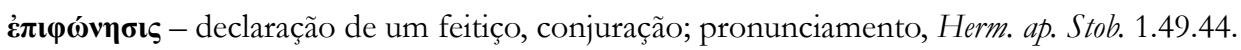

$\dot{\varepsilon} \boldsymbol{\pi} \iota \boldsymbol{\omega} \boldsymbol{\tau} \mathbf{\zeta} \boldsymbol{\omega}$ - iluminar, v. pas. no Corp. Herm. 13.21.

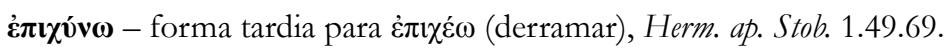

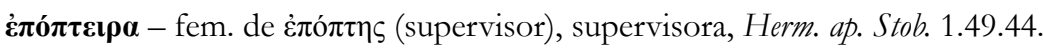

غ̇рó $\omega$ - amar, desejar, Corp. Herm. 1.4.

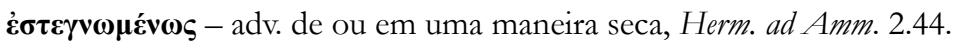

\footnotetext{
${ }^{15}$ Trata-se de uma palavra disparatada, desarrazoada, desprovida de nexo ou suspeita, sugerindo uma formulação alternativa que seja requerida pelo contexto. Segundo o aparato crítico de N.-F., há a

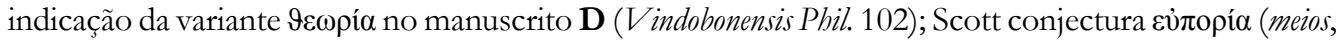

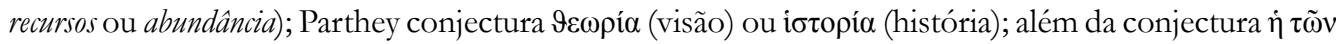
$\vartheta \varepsilon i ́ \omega v$ Ěvvoเ $\alpha$. Nock preferiu conservar a palavra Ẻvtopía entre duas cruces desperationis: para indicar que não há como proceder a uma conjectura ou formulação fidedigna e inequívoca (Lira, 2015, p. 121-2).
} 


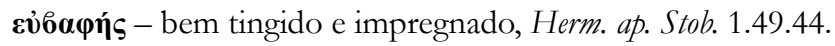

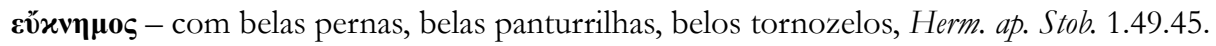

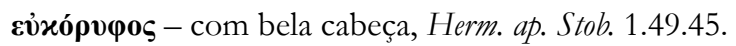

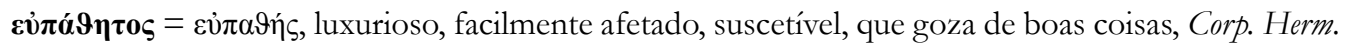
10.10 .

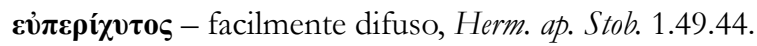

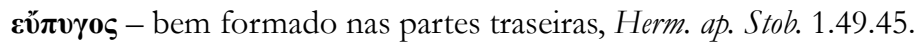

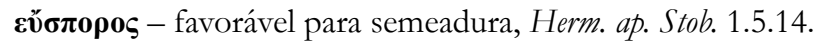

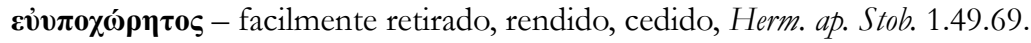

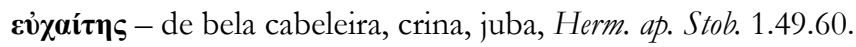

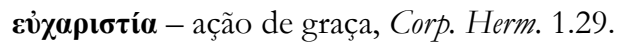

\section{Z}

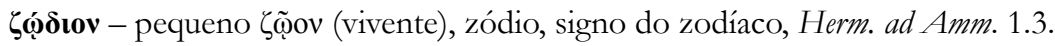

$\zeta \boldsymbol{\omega} \mathbf{v} \boldsymbol{\eta}$ - zona, uma das esferas planetárias, Corp. Herm. 1.25.

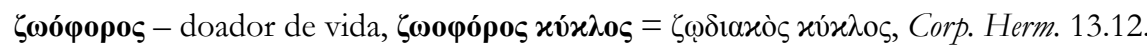

$\zeta \omega \tau \boldsymbol{\jmath} \boldsymbol{x} \boldsymbol{\varsigma} \varsigma$ - vital, característica da vida, Herm. ap. Stob. 1.41.7.

\section{H}

$\dot{\boldsymbol{\eta}} \lambda \mathbf{\imath} \boldsymbol{x} \mathbf{\imath} \boldsymbol{\alpha} \zeta \mathbf{o} \boldsymbol{\mu \alpha}$ - assumir esta ou aquela qualidade, dub. em Herm. ap. Stob. 1.49.69.

\section{$\Theta$}

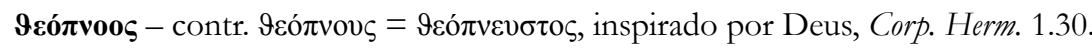

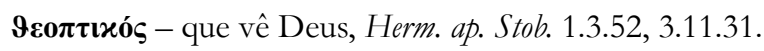

Үท́ $\boldsymbol{\rho}$ - besta, fera, animal, Corp. Herm. 10.20.

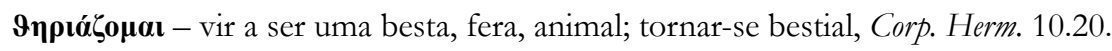

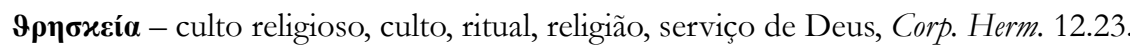

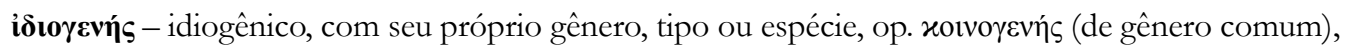
peculiar ao gênero, Herm. ap. Stob. 1.49.44.

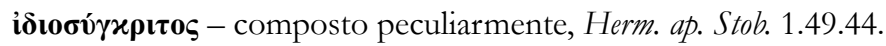

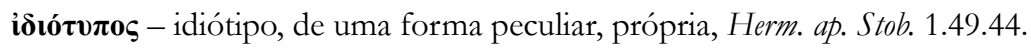


i $\lambda \boldsymbol{\alpha} \rho \mathbf{s} \varsigma$ - jubiloso, hilariante, alegre, contente, Corp. Herm. 1.4.

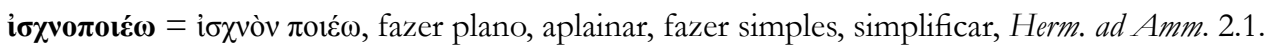

\section{K}

$\boldsymbol{\varkappa а 9 о \delta \eta \gamma o ́ \varsigma ~ = ~ o ́ \delta \eta \gamma o ́ s , ~ g u i a , ~ C o r p . ~ H e r m . ~ 1 . 2 6 . ~}$

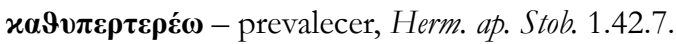

$\boldsymbol{\varkappa} \boldsymbol{\alpha} 9 \boldsymbol{v} \boldsymbol{\pi} \boldsymbol{\varepsilon} \boldsymbol{\tau} \boldsymbol{\varepsilon} \rho \boldsymbol{\eta} \boldsymbol{\sigma} \boldsymbol{\varsigma}$ - prevalência, prob. em Herm. ap. Stob. 1.42.7.

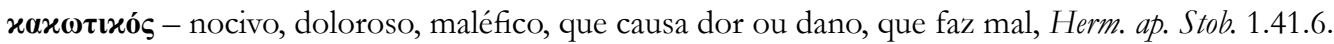

$\boldsymbol{x} \boldsymbol{\alpha} \lambda \boldsymbol{\lambda} \mathbf{i} \boldsymbol{9} \boldsymbol{\rho} \boldsymbol{\xi}$ - da prosa tardia, com bela cabeleira, Herm. ap. Stob. 1.49.45.

$\boldsymbol{x} \boldsymbol{\alpha} \lambda \lambda \mathbf{i} \mu \eta \boldsymbol{\eta} \boldsymbol{s}-\mathrm{com}$ belas coxas, Herm. ap. Stob. 1.49.45.

$\boldsymbol{x} \alpha \dot{\mu} \mu v \sigma ı \varsigma=x \alpha \tau \dot{\alpha} \mu v \sigma ı \varsigma$, piscadela, $\mathrm{o}$ fechar de olhos, Corp. Herm. 1.30.

$\boldsymbol{x} \boldsymbol{\alpha} \boldsymbol{\rho} \boldsymbol{\delta} \boldsymbol{i} \boldsymbol{\alpha}$ - coração, mente, sede da emoção e da razão, Corp. Herm. 4.11, 7.2.

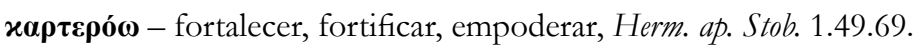

$\boldsymbol{x} \boldsymbol{\alpha} \boldsymbol{\alpha} \boldsymbol{\alpha} \boldsymbol{\alpha} \boldsymbol{v} v \omega=x \alpha \tau \alpha \beta \alpha \rho \varepsilon ́ \omega$, pesar de sono, cair de sono, fazer vergar pesadamente com sono, pesar sobre, sobrecarregar, Corp. Herm. 2.9 (v. pas.).

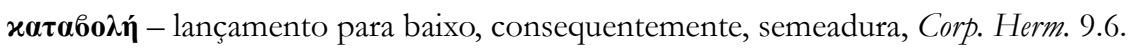

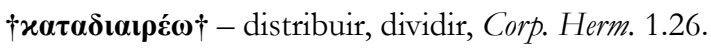

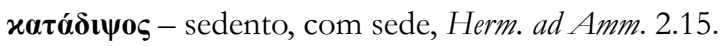

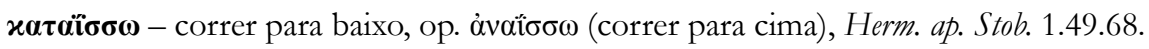

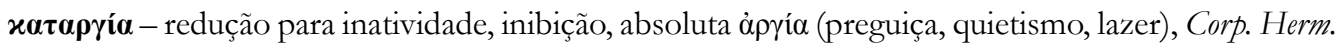
10.5 .

$\boldsymbol{\varkappa} \boldsymbol{\alpha} \boldsymbol{\alpha} \boldsymbol{\rho} \boldsymbol{\chi} \boldsymbol{\eta}$ - início, Herm. ad Amm. 2.14.

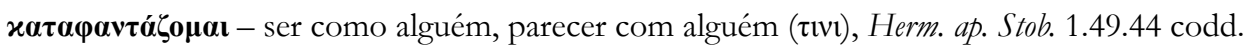

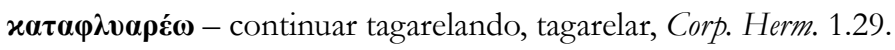

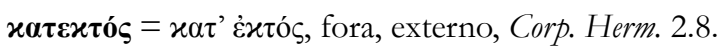

$\boldsymbol{\varkappa} \boldsymbol{\alpha} \varepsilon \pi \varepsilon \boldsymbol{\mu} \boldsymbol{\alpha} \boldsymbol{\alpha} \mathbf{v} \boldsymbol{\omega}$ - plantar o pé de alguém firmemente sobre, Corp. Herm. 18.16.

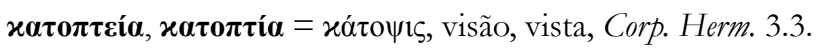

$\boldsymbol{\varkappa \alpha \tau \omega \varphi \varepsilon \rho \eta ́ \varsigma ~ - ~ c o m ~ t e n d e ̂ n c i a ~ p a r a ~ b a i x o , ~ p e s a d o , ~ o p . ~ \alpha ̀ v \omega \varphi \varepsilon \rho \eta ́ s ~ ( c o m ~ t e n d e ̂ n c i a ~ p a r a ~ b a i x o ) , ~ H e r m ~ a p . ~}$ Stob. 1.49.68.

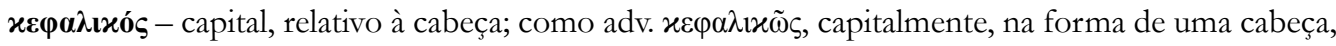
Corp. Herm. 10.11.

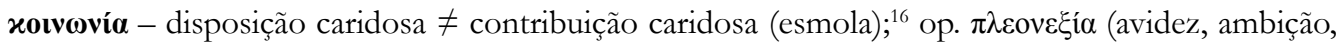
grandiosidade, superioridade), Corp. Herm. 13.9.

${ }^{16}$ Cf. Rm15.26, Hb13.16 (Novum Testamentum). 


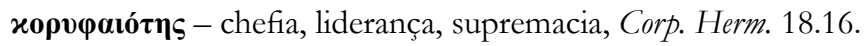

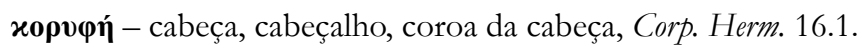

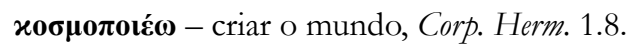

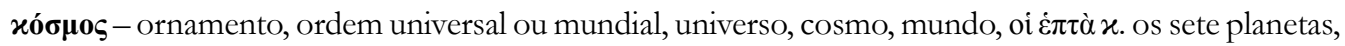

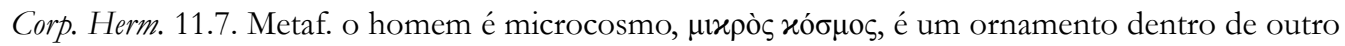

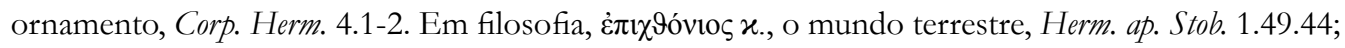
ó $\mu \varepsilon \tau$ ́́ $\rho \sigma t o \varsigma$ x., qualquer região do universo, Herm. ap. Stob. 1.49.44.

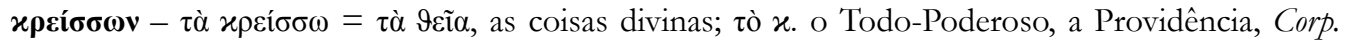
Herm. 18.11.

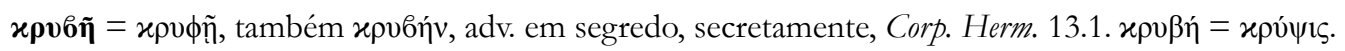

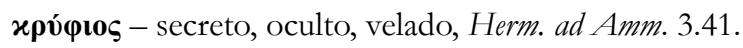

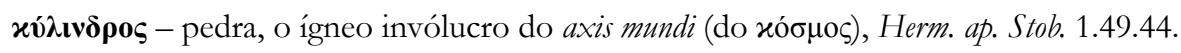

\section{$\Lambda$}

$\lambda \mathbf{i} \psi$ - oeste, op. $\dot{\alpha} \pi \eta \lambda \iota \omega ́ \tau \eta \varsigma$ (leste), Herm. ap. Stob. 1.21.9, 1.49.45.

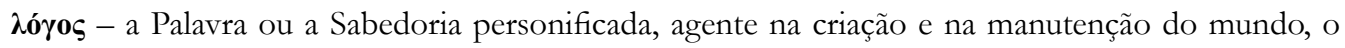
Divino Logos, Corp. Herm. 1.5, 6.

\section{$\mathbf{M}$}

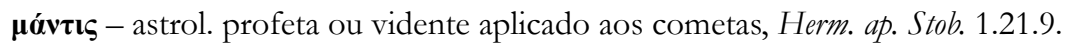

$\boldsymbol{\mu} \boldsymbol{\varepsilon} \boldsymbol{\gamma} \boldsymbol{\alpha} \boldsymbol{\lambda} \mathbf{o ́} \boldsymbol{\delta} \mathbf{o} \mathbf{0} \mathbf{\varsigma}$ - mui glorioso, Herm. ap. Stob. 1.49.44.

$\boldsymbol{\mu} \boldsymbol{\varepsilon} \boldsymbol{\gamma} \boldsymbol{\alpha} \boldsymbol{\lambda} \mathbf{0 \sigma} \boldsymbol{9} \boldsymbol{\varepsilon} \boldsymbol{v} \boldsymbol{s}$ - força, Herm. ap. Stob. 1.49.44.

$\boldsymbol{\mu} \boldsymbol{\varepsilon} \mathbf{\omega} \boldsymbol{\tau} \mathbf{o ́} \varsigma$ - sujeito à diminuição, Herm. ap. Stob. 1.10.15.

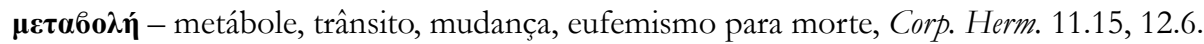

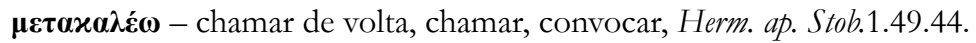

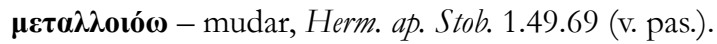

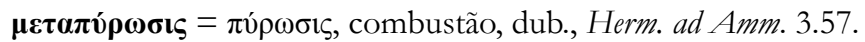

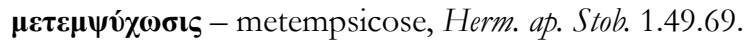

нєтролоเє́ஸ - fazer por medida, fazer sob medida, metrificar, Herm. ap. Stob. 49.69 (v. pas.).

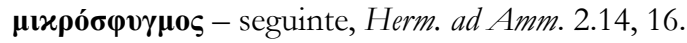

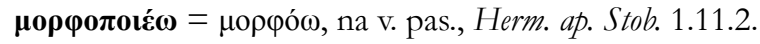

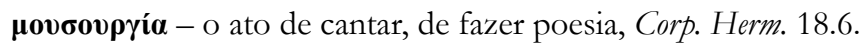

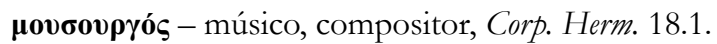

$\boldsymbol{\mu \nu \sigma \tau i ́ p ı o v ~ - ~ m i s t e ́ r i o , ~ s e g r e d o ~ r e v e l a d o ~ p o r ~ D e u s , ~ u m a ~ v e r d a d e ~ r e l i g i o s a , ~ m i ́ s t i c a ~ e ~ p i e d o s a , ~ C o r p . ~}$ Herm. 1.16, passim. 


\author{
$\mathbf{N}$ \\ мєаролоเє́ஸ - fazer(-se) novo, renovar, Herm. ap. Stob. 1.49.44. \\ мволоเє́ஸ - renovar, rejuvenescer, Herm. ap. Stob. 1.41.8.

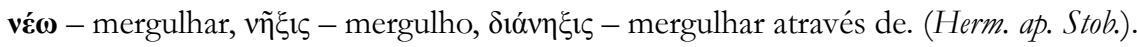

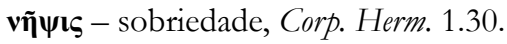 \\ voepós - mental, intelectual, intelectivo, Herm. ap. Stob. 1.49.44.

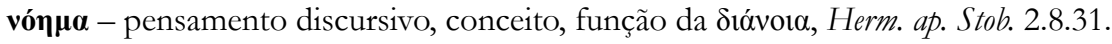

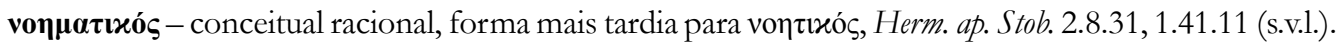

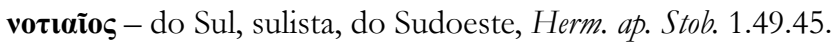

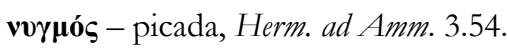

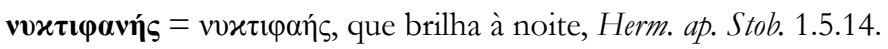

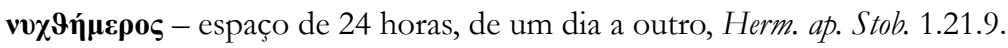

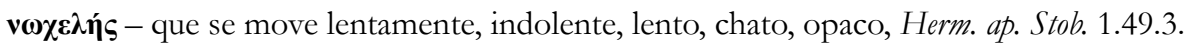

\title{
$\mathbf{O}$
}

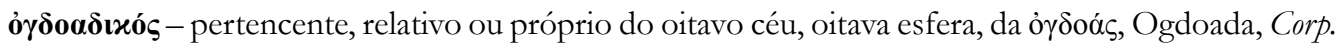
Herm. 1.26.

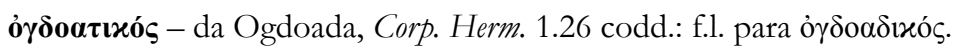

ơyxó ( - avolumar, aumentar, inchar, inflar (de orgulho), Corp. Herm. 8.3.

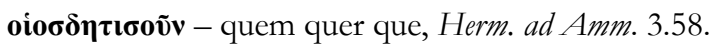

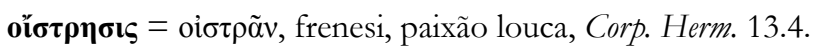

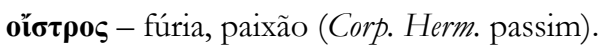

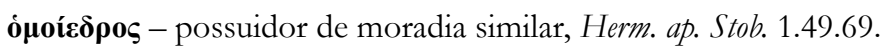

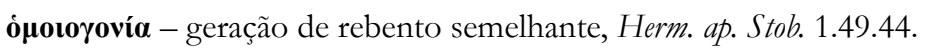

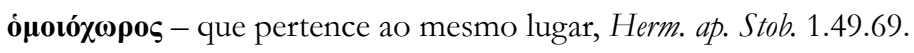

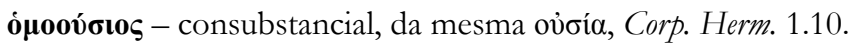

$\mathbf{0} \boldsymbol{\xi} \mathbf{v} \omega \boldsymbol{\pi} \mathbf{n} \boldsymbol{s}$ - de vista penetrante, Herm. ap. Stob. 1.49.45.

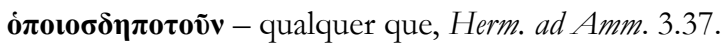

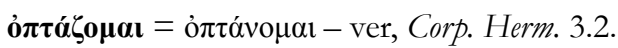

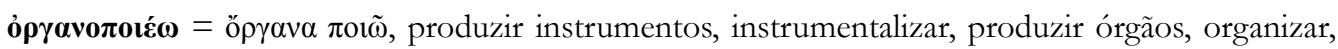
Corp. Herm. 9.6.

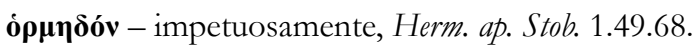

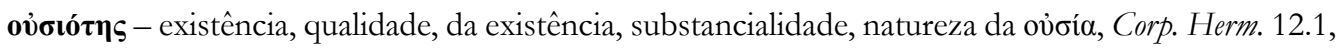
Herm. ap. Stob. 1.41.4. 
ov̉

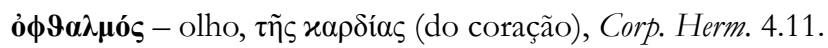

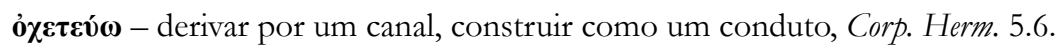

\section{II}

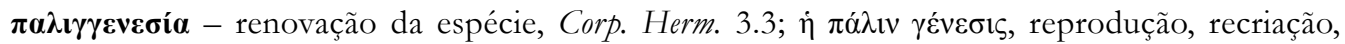
regeneração, novo nascimento, novo estado da existência, nova vida $=\mu \varepsilon \tau \varepsilon v \sigma \omega \mu \alpha \dot{\tau} \tau \omega \sigma \iota \varsigma$, Corp. Herm. 13.1.

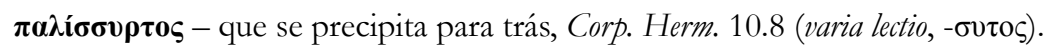

$\boldsymbol{\pi} \boldsymbol{\alpha} \boldsymbol{v} \boldsymbol{\alpha} \boldsymbol{x} \boldsymbol{\eta} \boldsymbol{\rho} \boldsymbol{\alpha} \boldsymbol{\tau} \mathbf{s}$ - totalmente incontaminado, Corp. Herm. 18.12.

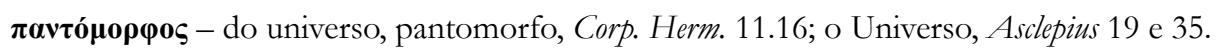

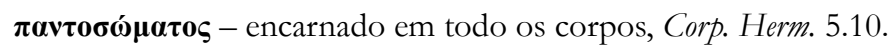

$\boldsymbol{\pi} \boldsymbol{\alpha} \boldsymbol{\omega} \boldsymbol{\varepsilon} \boldsymbol{\lambda} \boldsymbol{\eta} \boldsymbol{s}$ - totalmente benéfico, prob. em Herm. ap. Stob. 1.49.44.

$\boldsymbol{\pi} \boldsymbol{\alpha \rho \alpha} \boldsymbol{\varepsilon} \boldsymbol{\mu} \boldsymbol{\tau} \boldsymbol{\tau} \boldsymbol{\varepsilon} \boldsymbol{\omega} \boldsymbol{\omega}$ - transgredir uma lei, Herm. ap. Stob. 1.49.45.

$\boldsymbol{\pi} \boldsymbol{\alpha \rho \alpha} \mathbf{9} \boldsymbol{\lambda} \mathbf{b} \boldsymbol{\omega}$ - pressionar perto, Herm. ap. Stob. 1.49.68.

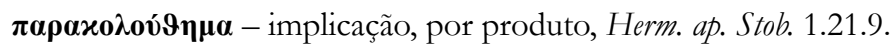

$\boldsymbol{\pi} \boldsymbol{\alpha} \boldsymbol{\alpha} \boldsymbol{\lambda} \dot{\eta} \boldsymbol{\pi} \boldsymbol{\tau} \boldsymbol{\omega} \boldsymbol{\rho}$ - herdeiro, Herm. ap. Stob. 1.49.44.

$\boldsymbol{\pi} \boldsymbol{\alpha} \rho \boldsymbol{\rho} \boldsymbol{\delta} \varepsilon \boldsymbol{v} \boldsymbol{\omega}$ - passar por ou através de, Herm. ap. Stob. 1.49.44.

$\boldsymbol{\pi} \tilde{\boldsymbol{\alpha}} \boldsymbol{\varsigma}$ - que consiste ou é composto totalmente de, Corp. Herm. 13.2; 11.2.

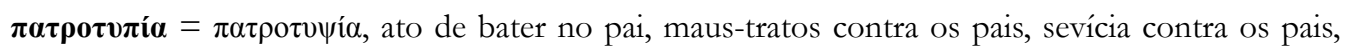
Corp. Herm. 9.3 (pl.).

$\boldsymbol{\pi} \boldsymbol{\alpha} \boldsymbol{\chi} \boldsymbol{v} \boldsymbol{v} \omega$ - engordar, Herm. ap. Stob.1.49.68.

$\boldsymbol{\pi \varepsilon \rho \alpha \tau o ́} \boldsymbol{\omega}$ - levar a um fim, executar, realizar, Corp. Herm. 18.11.

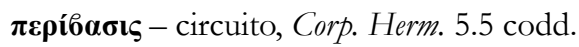

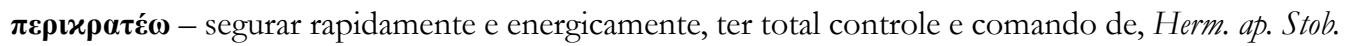
1.49.44.

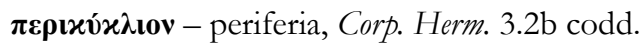

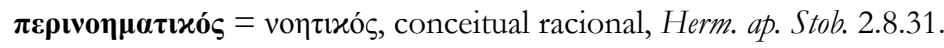

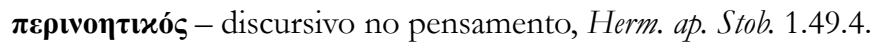

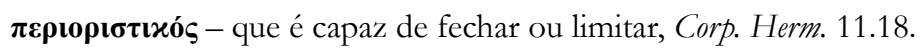

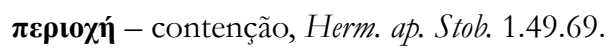

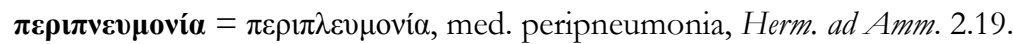

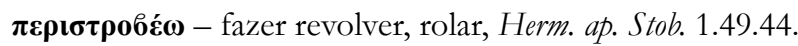

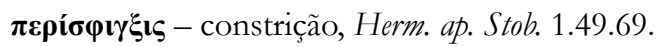


$\boldsymbol{\pi \varepsilon \rho i ́} \chi \boldsymbol{v} \boldsymbol{\mu \alpha}$ - atmosfera, Herm. ap. Stob. 1.49.44.

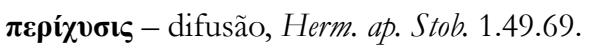

$\boldsymbol{\pi} \boldsymbol{\lambda} \boldsymbol{\alpha} \boldsymbol{\delta} \boldsymbol{\alpha} \boldsymbol{\rho} \boldsymbol{\tau} \tau \boldsymbol{\eta} \boldsymbol{-}$ - flacidez, Herm. ap. Stob. 1.49.69.

$\boldsymbol{\pi} \boldsymbol{\lambda} \boldsymbol{\alpha} \boldsymbol{\sigma} \boldsymbol{\tau} \boldsymbol{\rho} \boldsymbol{\imath} \boldsymbol{\alpha}$ - criadora, modeladora, Herm. ap. Stob. 1.49.69.

$\boldsymbol{\pi} \lambda \boldsymbol{\eta} \rho \omega \boldsymbol{\mu \alpha}$ - completude, massa, complexo, pleroma, Corp. Herm. 6.4, 12.15.

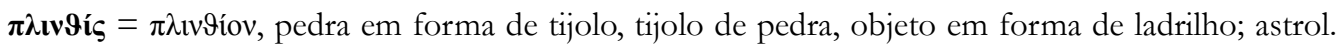
quadrante solar, Corp. Herm. 16.13.

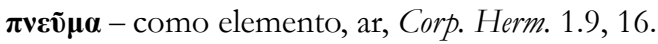

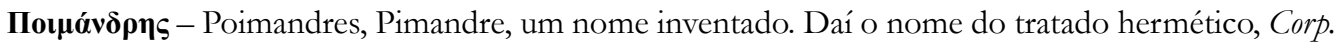
Herm. 1.2. ${ }^{17}$

$\boldsymbol{\pi} \mathbf{0} \boldsymbol{\lambda} \boldsymbol{v} \boldsymbol{\mu} \boldsymbol{\imath} \boldsymbol{\gamma} \boldsymbol{\eta} \varsigma$ - muito misturado, Herm. ap. Stob. 1.49.3.

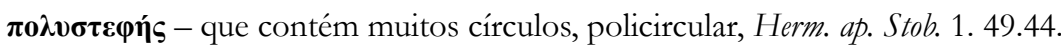

$\boldsymbol{\pi} \mathbf{0} \boldsymbol{\lambda} \boldsymbol{\sigma} \boldsymbol{\sigma} \boldsymbol{\mu} \boldsymbol{\mu} \boldsymbol{\alpha} \boldsymbol{\tau} \mathbf{\varsigma}$ - que tem muitos corpos, com muitos corpos, polissomático, multissomático, policorpóreo, multicorpóreo, Corp. Herm. 5.10.

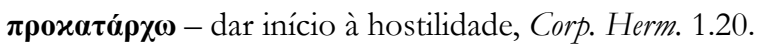

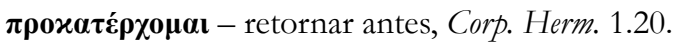

$\boldsymbol{\pi} \boldsymbol{\rho} \boldsymbol{\alpha} \boldsymbol{\alpha} \boldsymbol{\alpha} \boldsymbol{\mu} \boldsymbol{b} \boldsymbol{\alpha} \boldsymbol{v} \boldsymbol{\omega}$ - dar o voto de condenação, condenar, Corp. Herm. 12.3.

$\boldsymbol{\pi} \boldsymbol{\rho} \mathbf{\lambda} \boldsymbol{\eta} \boldsymbol{\mu} \boldsymbol{\mu \alpha}$ - pré-possessão, prejuízo, Corp. Herm. 12.3.

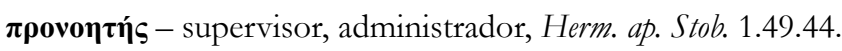

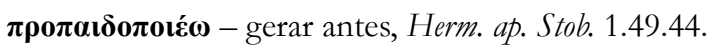

$\boldsymbol{\pi \rho о \pi} \boldsymbol{\alpha} \boldsymbol{\tau} \boldsymbol{\rho}$ - ancestral, antepassado, Herm. ap. Stob. 1.49.44, 3.11.31.

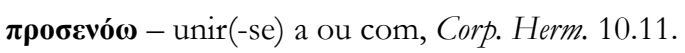

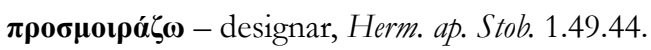

$\boldsymbol{\pi} \boldsymbol{\tau} \mathbf{\imath} \mathbf{o} \boldsymbol{\omega}$ - ser dotado de asas, ter asas, Herm. ap. Stob. 1.49.69.

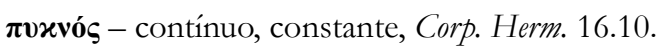

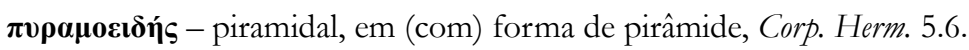

\section{$\mathbf{P}$}

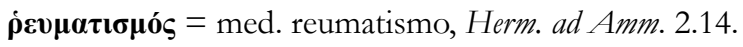

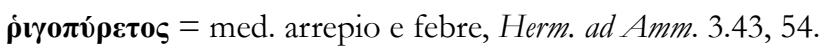

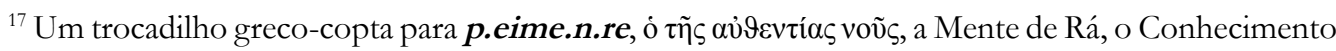
do Deus-Sol, a Mente da Soberania (Dodd, 1954, p. 99, n. 1).
} 


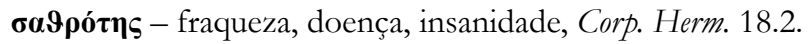

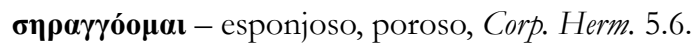

бипvолоเó - feitor, fazedor de tendas, de corpos, Herm. ap. Stob. 1.49.69.

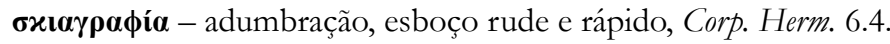

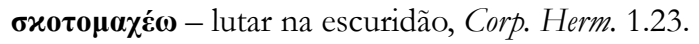

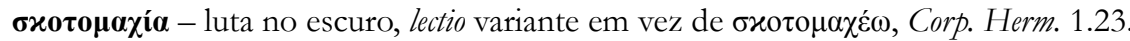

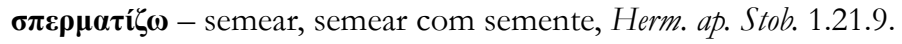

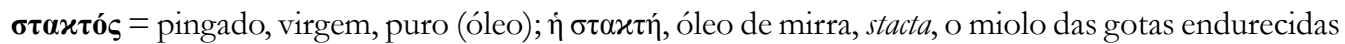
da mirra que serve para fazer o pó da resina odorífica, Herm. ad Amm. 3.1.

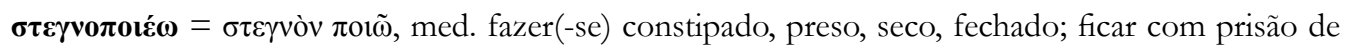
ventre, Herm. ad Amm. 3.46.

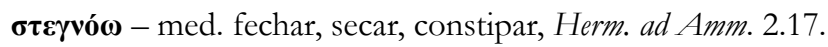

$\boldsymbol{\sigma \tau} \boldsymbol{\varepsilon} \gamma \mathbf{v} \boldsymbol{\omega} \boldsymbol{\sigma} \mathbf{\iota}$ - med. constipação, Herm. ad Amm. 3.22.

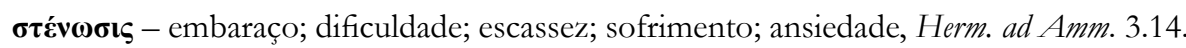

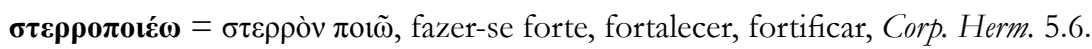

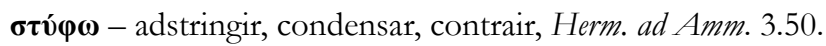

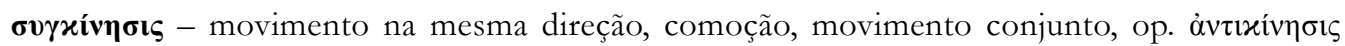
(movimento na direção contrária), Corp. Herm. 2.6.

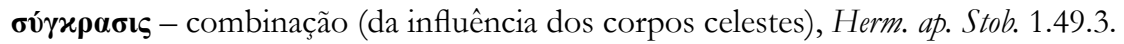

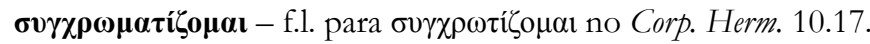

$\boldsymbol{\sigma} \boldsymbol{\gamma} \chi \boldsymbol{\rho} \boldsymbol{\omega} \tau \mathbf{i} \zeta \mathbf{0 \mu \alpha}$ - estar em contato (contagioso) com, Corp. Herm. 10.17 (codd. Stob.).

$\boldsymbol{\sigma} \boldsymbol{\gamma} \chi \omega \boldsymbol{\omega} \boldsymbol{\eta} \boldsymbol{\tau} \boldsymbol{x} \boldsymbol{x} \boldsymbol{s} \varsigma$ - que designa um lugar para, Herm. ap. Stob. 1.18.3.

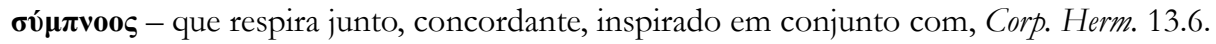

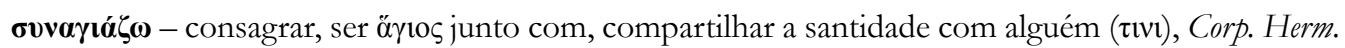
1.32 .

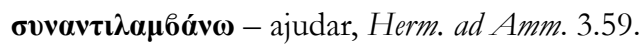

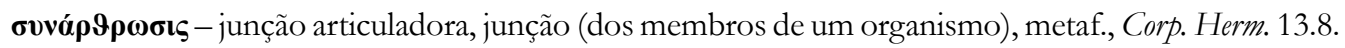

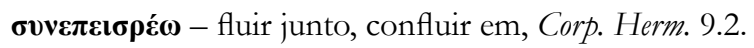

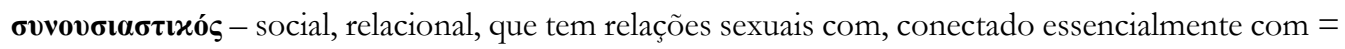
ovvoúcios, Corp. Herm. 12.19.

$\boldsymbol{\sigma} \boldsymbol{\sigma} \boldsymbol{\chi} \boldsymbol{\varepsilon} \tau \boldsymbol{\tau}$ ṕpıv - repositório, lugar de confinamento, Herm. ap. Stob. 1.49.68.

$\boldsymbol{\sigma} \chi \tilde{\boldsymbol{\eta}} \boldsymbol{\mu \alpha}=\delta$ เó $\gamma \rho \alpha \mu \alpha$, figura, diagrama, o planeta Marte, Herm. ad Amm. 1.1-2.12.

$\boldsymbol{\sigma} \chi \boldsymbol{\eta} \boldsymbol{\mu} \boldsymbol{\alpha} \boldsymbol{\tau} \boldsymbol{\tau} \tau \boldsymbol{\eta} \varsigma$ - figuratividade, esquematização, forma tardia para $\sigma \chi \tilde{\eta} \mu \alpha$, forma, figura, Herm. ap. Stob. 1.4.8. 
$\boldsymbol{\sigma} \boldsymbol{\chi} \mathbf{0} \boldsymbol{\lambda} \boldsymbol{\alpha} \zeta \boldsymbol{\omega}$ - estar vacante, desocupado (lugar), Herm. ap. Stob. 1.49.68.

$\boldsymbol{\sigma} \boldsymbol{\omega} \boldsymbol{\mu} \boldsymbol{\alpha} \boldsymbol{\tau} \boldsymbol{\zeta} \boldsymbol{\zeta} \boldsymbol{\omega}$ - incorporar, corporificar, Herm. ap. Stob. 1.49.45.

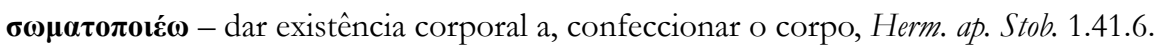

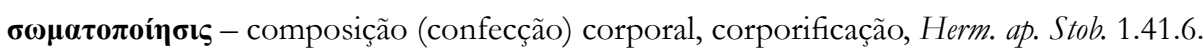

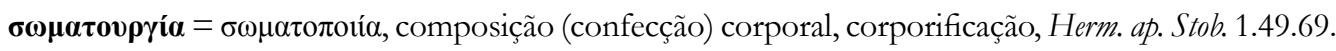

$\boldsymbol{\sigma} \boldsymbol{\omega} \boldsymbol{\mu} \boldsymbol{\alpha} \tau \boldsymbol{\omega} \boldsymbol{\sigma} \mathbf{\varsigma}$ - incorporação, formação do corpo, confecção corporal, Herm. ap. Stob. 1.41.6.

\section{$\mathbf{T}$}

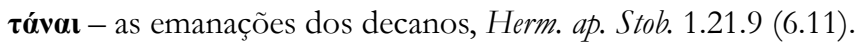

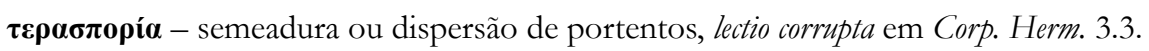

$\boldsymbol{\tau} \boldsymbol{\varepsilon} \boldsymbol{\rho} \boldsymbol{\alpha} \boldsymbol{\gamma} \boldsymbol{\omega} \boldsymbol{v} \boldsymbol{i} \boldsymbol{\zeta} \boldsymbol{\omega}$ - astrol. estar nas quadraturas, Herm. ad Amm. 2.12, 3.5-13.

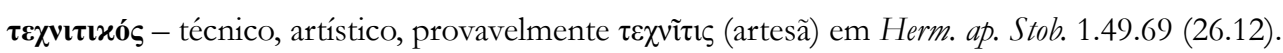

$\boldsymbol{\tau} \boldsymbol{\varepsilon} \chi \mathbf{v} \boldsymbol{0} \boldsymbol{\rho} \boldsymbol{\gamma} \boldsymbol{\eta} \boldsymbol{\mu \alpha}$ - obra de arte, Corp. Herm. 3.4.

$\boldsymbol{\tau} \boldsymbol{\varepsilon} \chi \mathbf{v o v \rho} \gamma \mathbf{i} \boldsymbol{\alpha}=\tau \varepsilon \chi v o u ́ \rho \gamma \eta \mu \alpha$ (obra de arte), Corp. Herm. 3.4.

то́ $\boldsymbol{\pi o s}$ - lugar, região, espaço, Corp. Herm. 2.12.

$\boldsymbol{\tau} \boldsymbol{\rho} \mathbf{\zeta} \boldsymbol{\zeta} \boldsymbol{\omega}$ - emissão de um grito estridente, Herm. ap. Stob. 1.49.44.

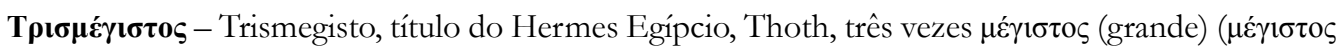
xaì $\mu$. xaì $\mu$.), Corp. Herm. passim.

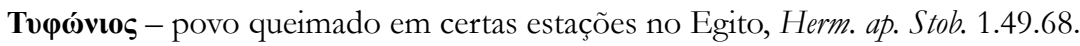

\section{Y}

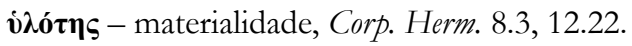

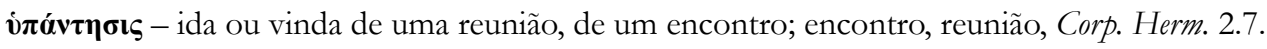

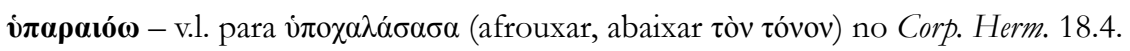

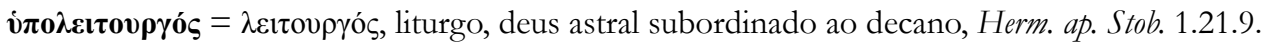

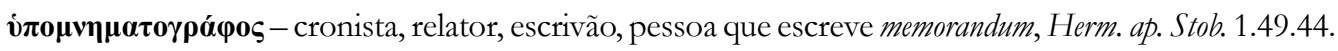

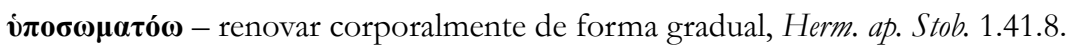

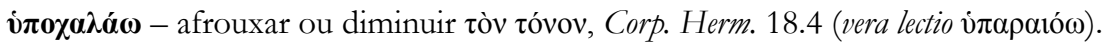

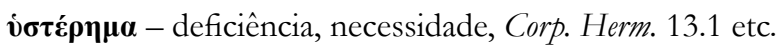

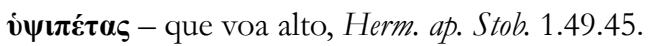

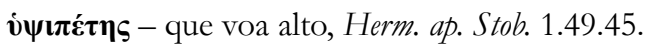




\section{$\Phi$}

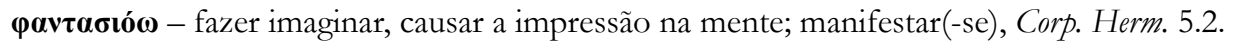

$\boldsymbol{\varphi \alpha ́ o s}=\varphi \tilde{\omega} \varsigma$, luz, Corp. Herm. 1.21.

$\boldsymbol{\varphi} 9 \boldsymbol{\varepsilon} \mathbf{p} \boldsymbol{\rho} \omega$ - corromper, destruir, perecer, Corp.Herm. passim.

$\boldsymbol{\varphi} 9 \mathbf{\rho} \boldsymbol{\rho} \boldsymbol{\mu} \mathbf{o}$ - destrutivo, perecível, Herm. ap. Stob. 1.49.44.

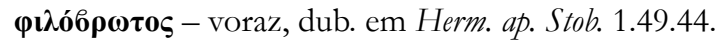

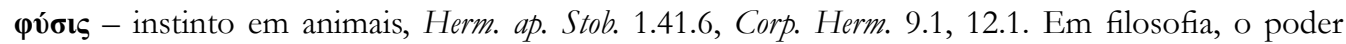
originador, Corp. Herm. 1.14; de forma concreta, a criação, a Natureza.

$\boldsymbol{\varphi \omega \tau i ́ \zeta \omega ~ - ~ i l u m i n a r ~ ( c o m ~ l u z ~ e s p i r i t u a l ~ e ~ d i v i n a ) , ~ C o r p . ~ H e r m . ~ 9 . 3 , ~ 1 3 . 1 8 . ~}$

\section{$\mathbf{X}$}

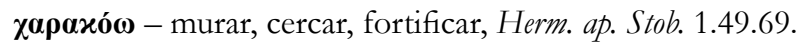

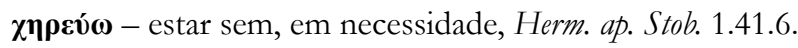

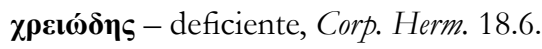

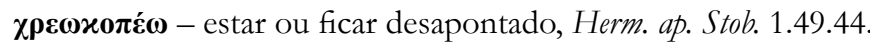

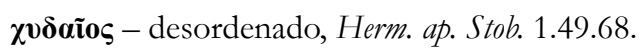

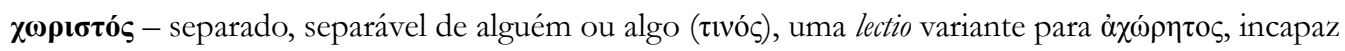
de conter ou abarcar, no Corp. Herm. 2.14.

\section{$\Psi$}

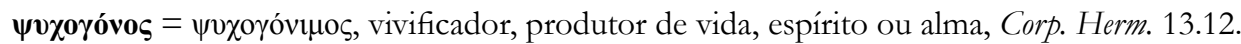

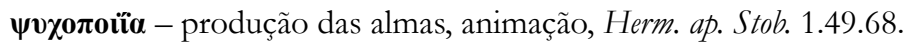

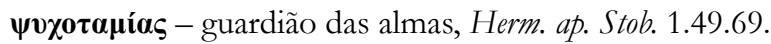

\section{$\boldsymbol{\Omega}$}

ஸробхоли́́ - astrol. observar o horóscopo, traçar o horóscopo; estar no ascendente, ascender na hora natal, Herm. ad Amm. 3.59.

\section{CONSIDERAÇÕES}

Além dos lemas supramencionados, inevitavelmente, deve-se proceder a uma explanação mais aplicada ou a uma aplicação através de outras palavras, a fim de que a

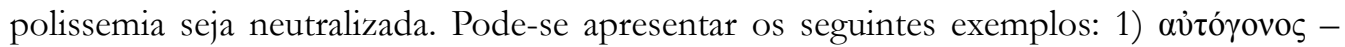

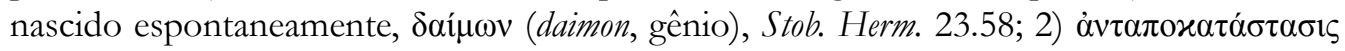


$=\dot{\eta}$ oủx $\dot{\alpha} \pi \mathrm{x} \alpha \boldsymbol{\alpha} \alpha \dot{\sigma} \sigma \alpha \sigma \mathrm{t}$, destruição, renovação por substituição Corp. Herm. 11.2, posição

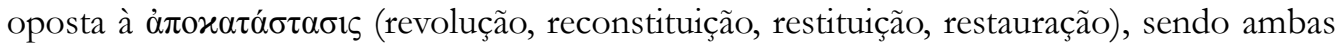

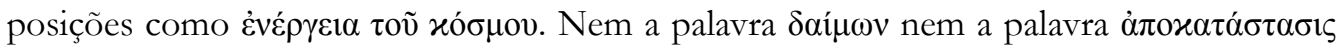
são incidentes na lista de lemas. Assim, coube evidenciar seu significado relacional ou seu oposto. O Glossário dos Hermetica Graca buscou também aproximar o sentido às variações da língua portuguesa (em alguns casos). Exemplo: $\gamma \alpha \sigma \tau \rho \mu \alpha \rho \gamma i ́ \alpha$ - ingestão excessiva, glutoneria (glutonaria), gula, Corp. Herm. 6.3.15.

O presente Glossário é parte de uma pesquisa lexical mais ampla acerca das palavras incidentes nos textos herméticos gregos. Objetiva-se, a posteriori, ampliar o estudo das palavras incidentes nos tratados herméticos. Convém explicar que o Glossário do Corp. Herm. fez parte da pesquisa bibliográfica do projeto de tradução do Corpus Hermeticum Gracum Texto Bilíngue (Grego-Português), desmembrando-se para a atual pesquisa de um Léxico dos Hermetica Graca, expandindo-se para outros objetivos e tendo uma extensão maior de lemas. A presente pesquisa visa ao estudo da lexicografia bilíngue dos Hermetica Graca. O Léxico dos Hermetica Graca visa compreender mais de 1000 entradas ou lemas.

No Brasil, a pesquisa sobre o hermetismo antigo e sobre os escritos herméticos é incipiente, mas já sinaliza produções significativas. As traduções dos textos herméticos desde o grego, o copta, o latim, árabe até o armênio são de relevância capital e devem ser estimadas com acurácia. Há no Brasil um esforço para garantir uma pesquisa literária, filológica e linguística dos escritos herméticos antigos, inserida, outrossim, em uma perspectiva históricocrítica, filosófica e religiosa.

Sendo assim, o presente texto tenta ser um instrumento de pesquisa a quem se interessa e busca uma aproximação em âmbito literário, linguístico e filológico do hermetismo e da Literatura Hermética. Deveras, o presente texto não é senão uma representação de um glossário grego-português com o objetivo de frisar as palavras mais usualmente empregadas nos Hermetica Graca. Além disso, convém considerar que as definições do hermetismo não se esgotam através de uma simples lista de palavras, nem tampouco o número de palavras é o mais fiel ao interesse de muitos.

\section{REFERÊNCIAS}

ADRADOS, Francisco Rodríguez. Diccionario Griego-Español (DGE). Madrid: ILC/ CCHS / CSIC, s/d. Disponível em: http://dge.cchs.csic.es/xdge/. Acesso em: 4 fev. 2021.

APOSTOLIDES SOPHOCLES, Evangelinus. Greek Lexicon of the Roman and Byzantine Periods (from B.C. 146 to A.D. 1100). New York: Adegi Graphics LLC, 2011. 1188 p. (Elibron Classics series).

BERTOLINI, Marco. Sul lessico filosofico dell" "Asclepius". Annali della Scuola Normale Superiore di Pisa, Classe di Lettere e Filosofia, serie 3, v. 15, n. 4, p. 1151-209, 1985.

COPENHAVER, Brian P. (trad.). Hermetica: The Greek Corpus Hermeticum and the Latin Asclepius in a new English translation, with notes and introduction by Brian P. Copenhaver. New York: Cambridge University Press, 2000. 404 p. 
DELATTE, Louis; GOVAERTS, Suzanne; DENOOZ, Joseph. Index du Corpus Hermeticum. Roma: Edizioni dell'Ateneo e Bizzari, 1977. 359 p. (Lessico Intellettuale Europeo, 13).

DODD, Charles Harold. The Bible and the Greeks. $2^{\text {nd }}$. imp. London: Hodder and Stoughton, 1954. 264 p.

DODD, Charles Harold. The interpretation of the Fourth Gospel. Reprinted Paperback Edition. Cambridge: Cambridge University Press, 2005. 478 p.

ECO, Umberto. Como se faz. uma tese. 2. ed. São Paulo: Perspectiva, 1985. 184 p. (Coleção Estudos, 85).

FESTUGIÈRE, André-Jean. La révélation d'Hermès Trismégiste. Paris: Les Belles Letres, 2014. 2062 p.

IDELER, Julius Ludwig. Physici et medici graeci minores. Berlin: Typis et Impensis G. Remeri, 1891. v. 1. 440p.

KAHLMEYER-MERTENS, Roberto S. et al. Como elaborar projetos de pesquisa: linguagem e método. Rio de Janeiro: FGV, 2009. 140 p. (Coleção FGV Prática).

LIDDELL, Henry George; SCOTT, Robert. A Greek-English Lexicon. Revised and augmented by Henry Stuart Jones with the assistance of Roderick McKenzie with the cooperation of many scholars. With revised supplement. Oxford: Claredon Press, 1996. (2438 p.).

LIRA, David Pessoa de. Grego antigo instrumental. João Pessoa: Ideia, 2021. 152 p.

LIRA, David Pessoa de. O batismo do coração no vaso do conhecimento: uma introdução ao hermetismo e ao Corpus Hermeticum. Recife: UFPE, 2015. 360 p.

LIRA, David Pessoa de. O bilinguismo greco-romano na tradução latina do $\Lambda \mathrm{OО} \Sigma$ TE $\Lambda$ EIO $\sum$ : enfoques sociolinguísticos na análise do Asclepius Latinus. Classica, v. 31, n. 1, p. 113-36, 2018. DOI: https://doi.org/10.24277/classica.v31i1.541

LIRA, David Pessoa de; CYROUS, Sam Hadji; VIEIRA, Otávio Santana. Iatromatemática: medicina holística e integrativa do hermetismo e do zoroastrismo. In: ECCO, Clóvis; SILVA, Rosemary Francisca Neves; QUADROS, Eduardo Gusmão; SIGNATES, Luiz (org.). Religião, Saúde e Terapias Integrativas. Goiânia: Espaço Acadêmico, 2016. v. 2, p. 103-17.

MAHÉ, Jean-Pierre (ed.). Hermès Trismégiste. Paralipomènes grec, copte, arménie: Codex VI Nag Hammadi, Codex Clarkianus 11 Oxoniensis, Définitions Hermétiques, divers. Paris: Les Belles Lettres, 2019. t. 5, CCLXX, 470 p. (Collection des Universités de France).

MARCONI, Marina de Andrade; LAKATOS, Eva Maria. Fundamentos de metodologia cientifica. 7. ed. São Paulo: Atlas, 2010. 297 p.

McLEAN, Bradley H. Hellenistic and biblical Greek. Cambridge: Cambridge University Press, 2014. 352 p. 
MIRANDA POZA, José Alberto. En torno a la palabra: sentido y forma. Estudios de Lexicografía y Lexicología. Madrid: Wisteria Ediciones, 2017.

NOCK, Arthur Darby; FESTUGIÈRE, André-Jean (ed.). Corpus Hermeticum. Edizione dei testi ermetici copti e commento di Ilaria Ramelli. Testo greco, latino e copto a fronte. Milano: Bompiani, Il pensiero occidentale, 2005. 1627 p.

NOCK, Arthur Darby; FESTUGIÈRE, André-Jean (ed.). Corpus Hermeticum. Texte établi par Arthur Darby Nock et traduit par André-Jean Festugière. $2^{\mathrm{e}}$ ed. Paris: Les Belles Lettres, 2011.2 t. 404 p. (Collection des Universités de France).

NOCK, Arthur Darby; FESTUGIÈRE, André-Jean. Préface et Introduction. In: NOCK, Arthur Darby; FESTUGIÈRE, André-Jean (ed). Corpus Hermeticum. $2^{\mathrm{e}}$ ed. Paris: Les Belles Lettres, 2011.t. 1 e 2, p. I-LIII, 259-95.

PARTHEY, Gustavus (ed.). Hermetis Trismegisti Poemander. Ad fidem codicum manu scriptorum recognovit Gustavus Parthey. Berolini: Libraria Fr. Nicolai, 1854. 134 p.

REALE, Giovanni. História da filosofia grega e romana. Ed. corr. São Paulo: Loyola, 2008. 9 v.

ROSSETTI, Livio. Introdução à filosofia antiga: premissas filológicas e outras "ferramentas de trabalho". São Paulo: Paulus, 2006. 440 p.

SCHIAVONE, Valeria. Natura e Origini del Corpus Hermeticum. In: SCHIAVONE, Valeria (ed.). Corpus Hermeticum: testo greco e latino a fronte. 3. ed. Itália: BUR (Biblioteca Universale Rizzoli), 2006. p. 5-52.

SCOTT, Walter (ed.). Hermetica: the ancient Greek and Latin writings which contain religious or philosophical teachings ascribed to Hermes Trismegistus. Boston: Shambala Publications, 1985. v. 1.549 p.

SCOT'T, Walter. Introduction. In: SCOT'T, Walter (ed.). Hermetica: the ancient Greek and Latin writings which contain religious or philosophical teachings ascribed to Hermes Trismegistus. Boston: Shambala Publications, 1985. v. 1.p. 1-111.

VAN DEN KERCHOVE, Anna. La voie d'Hermès: pratiques rituelles et traités hermétiques. Leiden: Brill, 2012. 440 p.

\section{REFERÊNCIAS ADICIONAIS PARA PESQUISA}

BERNAL, Martin. Black Athena. The Afroasiatic roots of classical civilization: the fabrication of ancient Greece 1785-1985. New Brunswick: Rutgers University Press, 2003 [1987]. v. 1. $575 \mathrm{p}$.

BETZ, Hans Dieter et al. (ed.). The Greek magical papyri in translation. Including the Demotic texts. Chicago: University of Chicago Press, 1986.339 p. 
BOUSSET, Wilhelm. Hauptprobleme der Gnosis: Forschungen zur Religion und Literatur des Alten und Neuen Testaments. Göttingen: Vandenhoeck und Ruprecht, 1973. 398 p.

BOUSSET, Wilhelm. Kyrios Christos: a history of the belief in Christ from the beginnings of Christianity to Irenaeus. Translated by John E. Steely Nashville: Abingdon Press, 1970. 496 p.

BRANDÃO, Junito de Souza. Mitologia grega. 23. ed. 6. reimpr. Petrópolis: Vozes, 2020. v. 2. 357 p.

BULL, Christian H. The tradition of Hermes Trismegistus: the Egyptian priestly figure as a teacher of Hellenized wisdom. Leiden: Brill, 2018. 532 p.

CHLUP, Radek. The ritualization of language in the Hermetica. Aries, São Paulo, v. 7, n. 2, p. 133-59, 2007.

ELIADE, Mircea. História das crenças e das ideias religiosas: de Gautama Buda ao triunfo do Cristianismo. Rio de Janeiro: Zahar, 2011. v. 2. 465 p.

FAIVRE, Antoine. Hermetism. In: JONES, Lindsay (ed.). Encyclopedia of Religion. $2^{\text {nd }}$ ed. Detroit, MI: Thomson/ Gale, Macmillan Reference USA, 2005. v. 6. p. 3944-56.

FAIVRE, Antoine. Note sur la transmission des traditions dans le contexte des courants esoteriques occidentaux modernes. In: KILCHER, Andreas B. (ed.). Constructing tradition: means and myths of transmission in Western esotericism. Leiden: Brill, 2010. p. 31-46 (Aries books series, 11).

FERRATER MORA, José. Diccionario de filosofía. 5. ed. Buenos Aires: Sudamericana, 1964. 2 t.

FESTUGIÈRE, André-Jean. Études d'histoire et de philologie. Paris: Vrin, 1975. 307 p.

FESTUGIÈRE, André-Jean. Hermetica: le baptême dans le cratère C.H., IV, 3-4. The Harvard Theological Review, v. 31, n. 1, p. 1-20, Jan. 1938.

FESTUGIÈRE, André-Jean. Le “logos” hermétique d'enseignement. Revue des Études Grecques, t. 55, fasc. 259-260, p. 77-108, janv.-juin 1942.

FOWDEN, Garth. The Egyptian Hermes: a historical approach to late pagan mind. Princeton: Princeton University Press, 1993. 244 p.

GLARE, Peter Geoffrey William (ed.). Oxford Latin Dictionary. $2^{\text {nd }}$ ed. reprinted with corrections. Oxford: Claredon, 2015. 2 v. 2344 p.

GONZÁLEZ BLANCO, Antonino. El Hermetismo. Ensayo bibliográfico. Anales de la Universidad de Murcia, v. 38, n. 2, p. 43-80, 1979-1980 (1981).

GONZÁLEZ BLANCO, Antonino. Misticismo y escatología en el Corpus Hermeticum. Cuaderno de Filología Clásica, n. 5, p. 313-60, 1973.

GRESE, William C. Corpus Hermeticum XIII and early Christian literature. Leiden: Brill Archive, 1979. 228 p. 
GURGEL PEREIRA, Ronaldo Guilherme. The hermetic logos: reading the "Corpus Hermeticum" as a reflection of Graeco-Egyptian mentality. Doctoral Thesis, University of Basel, Faculty of Humanities and Social Sciences, 2010. 255 p. Disponível em: http:/ / edoc. unibas.ch/diss/DissB_9262. Acesso em: 26/07/2021.

HANEGRAAFF, Wouter J. (ed.). Dictionary of gnosis and Western esotericism. Leiden: Brill, 2006. $1228 \mathrm{p}$.

HORMAN, John F. The text of the Hermetic literature and the tendencies of its major collections. A dissertation submitted to the School of Graduate Studies in partial fulfillment of the requirements for the degree Doctor of Philosophy. Hamilton, McMaster University, Nov. 1973. 349 p.

JONAS, Hans. The gnostic religion: the message of the alien god and the beginnings of Christianity. Featuring a newly translated introduction by the author. $3^{\text {rd }}$ ed. rev. Boston: Beacon Press, 2001. 355 p.

LAMPE, Geoffrey William Hugo. A patristic Greek lexicon. Oxford: Claredon, 1961. 1568 p.

LEWIS, Charlton T.; SHORT, Charles; FREUND, William. Latin Dictionary. Founded on Andrew's edition of Freund's Latin Dictionary. Revised, enlarged, an in great part rewritten by Charlton T. Lewis and Charles Short. Oxford: Claredon, 1958. 2019 p.

MAHÉ, Jean-Pierre. Hermès en haute-Egypte: les textes hermétiques de Nag Hammadi et leurs parallèles grecs et latins (i); Le fragment du discours parfait et les définitions hermetiques arméniennes (ii). Québec: Presses de l'Université Laval, 1982. 2 t. (Bibliothèque Copte de Nag Hammadi, 3, 7).

MORESCHINI, Claudio. Hermes Christianus: the intermingling of Hermetic piety and Christian thought. Turnhout: Brepols, 2011. 306 p. (Cursor mundi; v. 8).

NILSSON, Martin P. Krater. The Harvard Theological Review, v. 51, n. 2, p. 53-8, Apr. 1958.

NOCK, Arthur Darby. Conversion: the old and the new in religion from Alexander the Great to Augustine of Hippo. Lanham, MD: University Press of America, 1988. 309 p. (Brown classics in Judaica).

NOCK, Arthur Darby. Early Gentile Christianity and its Hellenistic background. New York: Harper \& Row, 1964. 155 p.

NORDEN, Eduard. Agnostos Theos: Untersuchungen zur Formengeschichte Religioeser Rede. 4. unveräenderte Aufl. Darmstadt: Wissenschaftliche Buchgesellschaft, 1956. 409 p.

PACHOUMI, Eleni. The concepts of the divine in the Greek magicalpapyri. Tübingen: Mohr Siebeck, 2017. $258 \mathrm{p}$.

PARROT, M. Douglas (ed). Nag Hammadi codices V, 2-5 and VI. The Coptic Gnostic Library. Edited with English translation, introduction and notes; published under the auspices of the Institute for Antiquity and Christianity. Leiden: Brill, 1978. v. 11. 553 p. 
PREISENDANZ, Karl et al. (ed.). Papyri graecae magicae. Die Griechischen Zauberpapyri. Stuttgart: Teubner, 1974 (1928-1931). $2 \mathrm{v}$.

REITZENSTEIN, Richard. Hellenistic mystery-religions: their basic ideas and significance. Translated by John E. Steely. Eugene (OR): Pickwick Publications, 1978. 572 p.

REITZENSTEIN, Richard. Poimandres: Studien zur Griechisch-Ägyptischen und frühchristlichen Literatur. Unveränderter anastatischer nachdruck. Leipzig: Teubner, 1922. 382 p.

SÖDERGÅRD, J. Peter. The Hermetic piety of the mind: a semiotic and cognitive study of the discourse of Hermes Trismegistos. Stockholm: Almqvist \& Wiksell International, 2003. 287 p. (Coniectanea biblica: New Testament series, 41).

TRÖGER, Karl-Wolfgang. Mysterienglaube und Gnosis in Corpus Hermeticum XIII. Berlin: Akademie-Verlag GmbH., 1971. 186 p. (Texte und Untersuchungen zur Geschichte der Altchristlichen Literatur, Band 110). 